\title{
Cyclonic activity in the Mediterranean region from a high-resolution perspective using ECMWF ERA5 dataset
}

\author{
Leonardo Aragão $^{1}$ (D) . Federico Porcù ${ }^{1}$ (D)
}

Received: 1 April 2021 / Accepted: 8 September 2021 / Published online: 15 October 2021

(C) The Author(s) 2021

\begin{abstract}
This study focuses on developing a new Cyclone Detection and Tracking Method (CDTM) to take advantage of the recent availability of a high-resolution reanalysis dataset of ECMWF ERA5. The proposed algorithm is used to perform a climatological analysis of the cyclonic activity in the Mediterranean Region (MR) into a 40-year window (1979-2018). The tuning of the new CDTM was based on the comparison with currently available CDTMs and verified through careful subjective analysis to fully exploit the finer details of MR cyclones features. The application of the new CDTM to the ERA5 high-resolution dataset resulted in an increase of $40 \%$ in the annual number of cyclones, mainly associated with subsynoptic and baroclinic driven lows. The main cyclogenetic areas and seasonal cycle were properly identified into the MR context, including areas often underestimated, such as the Aegean Sea, and emerging new ones with cyclogenetic potential such as the coast of Tunisia and Libya. The better cyclone features description defined three distinct periods of cyclonic activity in the MR with peculiar and persistent characteristics. In the first period (Apr-Jun), cyclones develop more frequently and present higher velocities and deepening rates. In the second (Jul-Sep), the cyclonic activity is governed by thermal lows spreading slowly over short tracks without reaching significant depths. In the last and longest season (Oct-Mar), cyclones become less frequent, but with the highest deepening rates and the lowest MSLP values, ranking this period as the most favourable to intense storms.
\end{abstract}

Keywords Cyclones $\cdot$ Tracking methods $\cdot$ Mediterranean region $\cdot$ ERA5 $\cdot$ Reanalysis $\cdot$ Climatology

\section{Introduction}

At mid-latitudes, the atmospheric dynamics are governed by exchanges of heat, humidity, and precipitation between the poles and the equator. Despite several well-known atmospheric teleconnections acting on annual and multidecadal scales, the cyclonic systems are a key player in driving meteorology and climate in these regions, daily shaping the meso-to-synoptic-scale patterns of the main atmospheric variables. These structures are often responsible for hydrometeorological hazards, such as heavy and persistent rain and strong winds (Porcù and Carrassi 2009; Messmer et al. 2015). For these reasons, and because of their well-defined structure, extra-tropical cyclones are used as climatic

Federico Porcù

federico.porcu@unibo.it

Leonardo Aragão

leonardo.aragao@unibo.it

1 Department of Physics and Astronomy "Augusto Righi”, University of Bologna, Bologna, Italy indicator, analysing the changes in their main characteristics across past and future decades (Pinto et al. 2007; Nissen et al. 2014; Befort et al. 2016; Catto et al. 2019).

The Mediterranean Region (MR) is a peculiar environment characterized by a closed sea ecosystem, relatively warm and surrounded by mountain chains. In addition, there are several densely populated cities in coastal areas, rich in assets and heritage. Such features place the MR in an exceptional group of environments (e.g., Sea of Japan, Bay of Bengal, South China Sea, Gulf of Mexico, Mozambique Channel, etc.) where the complex interplay of all these components makes these areas fragile, prone to natural and anthropogenic risks, and very sensitive to climate change (Giorgi 2006).

The idea to extensively study hydrometeorological hazards and climate change through the structure and dynamics of extra-tropical cyclones claims the availability of automatic tools, working on given meteorological field to detect and track such systems, and able to estimate their relevant characteristics. An effective cyclone tracking system has numerous applications in weather and climate studies: (1) 
revisit notable past events exploiting the enhanced capabilities of modern data assimilation systems (Liberato et al. 2011; Marra et al. 2019); (2) establish continuity between different decades, which is the key to understand changes in cyclonic activity (Trigo 2006; Priestly et al. 2020); and (3) evaluation of climate model outputs to evidence the expected modification in cyclone structures (Pinto et al. 2007; Catto et al. 2019), assessing possible increase of their impact on society (Leckebusch et al. 2007).

Since the late 80 s, many algorithms for identifying extratropical cyclones into large atmospheric datasets (reanalysis and climate projections) have been contributed to a better understanding of precipitation associated with frontal weather systems affecting the regional climate and, in particular, the water cycle and the weather extremes (Blender et al. 1997). Typically, these algorithms follow the standard two-step approach proposed by Lambert (1988): (1) the identification of possible cyclone centre position through the local minimum or maximum of a given atmospheric parameter (hereafter, candidates) within the study domain at each available timestep; and (2) the definition of cyclone's trajectory based on the nearest-neighbour search procedure, where a candidate identified in the previous timestep possibly travels the shortest distance to reach the position of the candidate identified in the current timestep.

Several Cyclone Detection and Tracking Methods (CDTMs) were developed for different regions of the globe: southern hemisphere (Murray and Simmonds 1991; Sinclair 1994), northern hemisphere (Pinto et al. 2005; Raible et al. 2008; Flaounas et al. 2014), both hemispheres (Hewson and Titley 2010; Neu et al. 2013), and also for particular regions as North Atlantic (Blender et al. 1997; and Trigo 2006) and MR (Trigo et al. 1999; Lionello et al. 2016). Moreover, a CDTM can also be applied to climate model.

In general, the main differences among CDTMs are the choice of the meteorological parameter under analysis (e.g. mean sea level pressure, geopotential height or vorticity), the data optimisation method applied to filter candidates in each timestep (e.g. terrain filtering or atmospheric variable limits), and the definition of a distance threshold for the cyclone's displacement between consecutive timesteps (Neu et al. 2013). Although summarised, a wide range of combinations and variations of these parameters define not only the advantages and disadvantages of each method but also the cyclone typology under investigation.

The recent availability of the high-resolution ERA5 reanalysis dataset (Hersbach et al. 2020) for a climatologically significant period (from 1950 to present) offers the possibility to perform a long-term detailed study of cyclonic structures and dynamics. Despite its recent availability (mid2018), ERA5 already shown its potentials in studying storm surge (Dullaart et al. 2020), cloud cover (Lei et al. 2020), atmospheric blocks and extratropical cyclones (Rohrer et al.
2020), and even small-scale hydrometeorological hazards (Taszarek et al. 2020).

The aim of this work is twofold: first, to introduce a new CDTM able to exploit the higher resolution of ERA5 dataset, evaluating the algorithm's sensitivity to increased spatial and temporal resolution in comparison with previous algorithms; and, second, to apply the new algorithm to study the cyclonic activity over the MR in the last 40 years.

In the next section, the ERA5 dataset and the study region are introduced, and the proposed CDTM is described presenting a strategy to assess the impact of increased resolution. In Sect. 3, the new CDTM is tuned on the main results reported in the literature, and on two case studies of notable cyclones analysed individually, while Sect. 4 is devoted to the complete climatological analysis carried on with the new algorithm. The last section summarizes the main results and presents the conclusions.

\section{Data and methods}

\subsection{ERA5 and Mediterranean Region}

This study's central database is ERA5, the fifth generation ECMWF atmospheric ReAnalysis of the global climate (Hersbach et al. 2020). Designed to provide hourly global data from 1950 to present, ERA5 combines modelled data with observations across the world into a globally complete and consistent dataset based on physics laws. The advantages upon its precursors (ERA40 and ERA-Interim) include significantly higher spatial and temporal resolutions, information on data quality variation over space and time, much-improved description of the troposphere, improved representation of tropical cyclones, better global balance of precipitation and evaporation, better precipitation over land in the deep tropics, better soil moisture representation, and more consistent sea surface temperature and sea ice (Hersbach et al. 2020).

ERA5 is being developed through the Copernicus Climate Change Service (C3S) using 4D-Var data assimilation in CY41R2 of ECMWF's Integrated Forecast System (IFS), which the main product provides atmospheric data distributed at 137 hybrid sigma/pressure vertical levels from the surface up to $0.01 \mathrm{hPa}$ top level. For ERA5 purposes, the atmospheric data are interpolated over 37 pressure levels and other 16 potential temperature levels and one potential vorticity level. The surface level presents additional 2D parameters such as total precipitation, $2 \mathrm{~m}$ temperature, $10 \mathrm{~m}$ wind components, radiation at the top of the atmosphere, and vertical integrals over the entire atmospheric column. Furthermore, as the IFS model operates coupled with a soil model and an ocean wave model, its quantities are available also on ERA5 surface data (Hersbach et al. 2020). The 
integration among observational data and the prediction model befalls through two modules: The Ensemble of Data Assimilation (EDA) and the High-RESolution realisation (HRES), which operate at different spatial and temporal resolutions, but result in a dataset of global hourly data distributed into a $0.25^{\circ} \times 0.25^{\circ}$ spacing grid.

The present study focuses on 40 years of ERA5 data (1979-2018), and its domain covers the MR defined by the area within $9^{\circ} \mathrm{W}$ to $42^{\circ} \mathrm{E}$ and $27^{\circ} \mathrm{N}$ to $48^{\circ} \mathrm{N}$ (Fig. 1). This definition permits a further comparison with Trigo et al. (1999) and Lionello et al. (2016), which presented a similar analysis using ERA-Interim with $1.5^{\circ}$ of spatial resolution, taken as a benchmark for developing our algorithm. Inside this window, the zonal distance between ERA5 grid-points ranges from $18.7 \mathrm{~km}$ along the northern edge of the domain, up to $24.8 \mathrm{~km}$ along with the southern one. To avoid border issues an additional belt of $6^{\circ}$ surrounding the MR was included (Fig. 1), expanding the domain to dimensions about $45^{\circ}$ of longitude and $33^{\circ}$ of latitude, and totalizing 33,649 gridpoints equally distanced by $0.25^{\circ}$.

\subsection{Cyclone tracking algorithms}

The improvement on spatial and temporal resolutions granted by ERA5 is expected to be crucial for a cyclone better description, allowing to capture its entire life cycle and to identify even the smaller and short-living systems (Pinto et al. 2005; Neu et al. 2013). This potential is expected to be very beneficial for the study of MR, where cyclones have shorter lifetime, travel shorter distances and present weaker horizontal pressure gradients than those common in other parts of the globe (Trigo et al. 1999, 2002; Raible et al. 2010; Lionello et al. 2016).

In the present work, the main challenge was to develop a new methodology suitable to identify cyclones with such a high-resolution and allow a reasonable comparison with the literature results, where the highest spatial resolutions were 5-10 times worse than ERA5, with timesteps of 6 or $12 \mathrm{~h}$. According to Blender and Schubert (2000), improvements in spatial resolution from $3^{\circ}$ to $1^{\circ}$ was already enough to produce significant changes in the total number of cyclones identified due to numerical noise resulting from a large volume of data, topography effects and detection of thermal lows. Such results motivated the development of new CDTMs enhanced by filtering techniques to mitigate weak cyclones' detection (Pinto et al. 2005; Wernli and Schwierz 2006; Simmonds et al. 2008; Raible et al. 2008; Hewson and Titley 2010; Hanley and Caballero 2012; Messmer et al. 2015).

According to Hodges et al. (2003), CTDMs based on mass related fields represent better lower frequency synoptic-scale motions, while those based on vorticity capture better higher frequency but often fail a few hundred kilometres the cyclone centre positions (Sinclair 1994). Since the MR presents several zones that naturally induce vorticity due to circulation effects on mountain and land-sea interface, also favouring the formation of small low-pressure areas or thermal lows, the present study uses the geopotential height

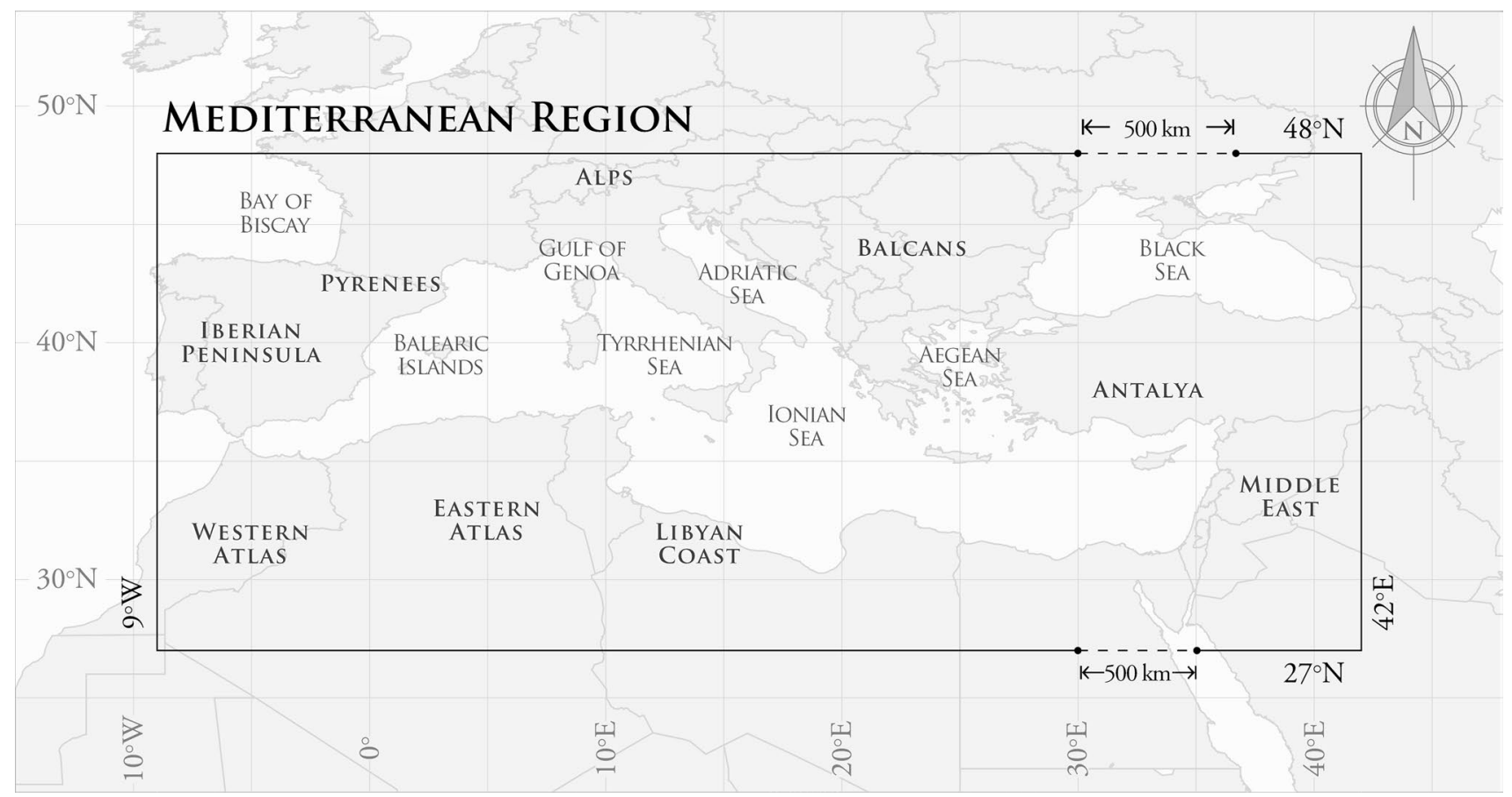

Fig. 1 The study domain and the Mediterranean Region 
field for the identification of the local minimums. In this case, we chose the $1000 \mathrm{hPa}$ level to trade-off the need to filter out minor surface disturbances and to still keep close to the Earth's surface, the cyclones' primary energy source.

The CDTM proposed in the present study has the same structure presented by Lambert (1988), which is divided into two distinct modules: The Cyclone Identification Module (CycID), and The Cyclone Track Module (CycTR). Initially, the first module is applied individually for all 350,640 hourly timesteps existing in the ERA5 dataset for 1979-2018 to identify gridpoints where a possible cyclonic structure is located. Later, the CycTR is employed to join these possible cyclonic structures and trace the path performed by each identified cyclone.

Figure 2 illustrates the CycID into three consecutive steps. The first one (Fig. 2a) evaluates the Geopotential Height at $1000 \mathrm{hPa}\left(Z_{1000}\right)$ of each gridpoint in the MR domain searching for local minimums (labelled as "candidates") over a $3 \times 3$ gridpoints neighbourhood. In the next step (Fig. 2b), the list of candidates found at each timestep passes through a filter to keep only the lowest local minimum within a $5^{\circ}$ $\times 5^{\circ}$ area $(21 \times 21$ gridpoints $)$. Although the analysis box appears to be very large ( $\sim 600 \mathrm{~km}$ wide), it is consistent to the typical extratropical cyclone sizes observed in the MR, which present average values of 500-550 km (Trigo et al. 1999), and much smaller than those of North Atlantic that ranges from 1000 to $2000 \mathrm{~km}$ (Nielsen and Dole 1992). Currently available CDTMs considers candidates into a $3 \times 3$ gridpoints matrix, something reasonable for methods based on low-resolution data where the analysis box ranges about 250-300 km wide. But, for datasets with a spatial resolution of the order of $30 \mathrm{~km}$, as ERA5, it reduces to boxes of
$50-60 \mathrm{~km}$ wide. Thus, the search matrix's enlargement was essential to define the actual cyclone's centre position and avoid identifying multiple candidates within the same lowpressure core area.

An additional filter closes the CycID (Fig. 2c) selecting only candidates related to an atmospheric depression with dimensions equivalent to the Rossby-deformation scale $(1000 \mathrm{~km})$. For doing so, the directional average of $Z_{1000}$ spatial gradients $\zeta_{D i r}(\mathrm{t})$ defined as

$\zeta_{\text {Dir }}(t)=\frac{1}{4} \sum_{i=1}^{4} \frac{d Z_{1000}\left(x_{i}, t\right)}{d x_{i}}$,

was computed for the eight principal directions (Dir) around each candidate position $($ Dir $=\{\mathrm{N}, \mathrm{NE}, \mathrm{E}, \mathrm{SE}, \mathrm{S}, \mathrm{SW}, \mathrm{W}$, NW\}, shaded areas in Fig. 2c) using gridpoints positioned approximately at $250,500,750$ and $1000 \mathrm{~km}\left(x_{i}\right)$ from the candidate. In the end, only gridpoints surrounded by eight positive $\zeta_{D i r}$ 's remained in the list of candidates. Although there are several filters for reducing numerical noise in high-resolution data (Blender et al. 1997), the criteria and thresholds used in the second and third steps of CycID are proposed in the present study based on the spatial and temporal resolutions of the ERA5 dataset.

After the CycID processing, the application of CycTR begins. Here, the lists of candidates identified at each timestep $t_{n}$ are evaluated chronologically to search the candidates' possible position in the subsequent timestep $t_{n+1}$. The candidate positions were combined using the Nearest Neighbour Method, where the searching box at timestep $t_{n+1}$ was set to $21 \times 21$ gridpoints around the candidate position at timestep $t_{n}$ (as in the second step of a

\section{CANDIDATE}

SEARCH

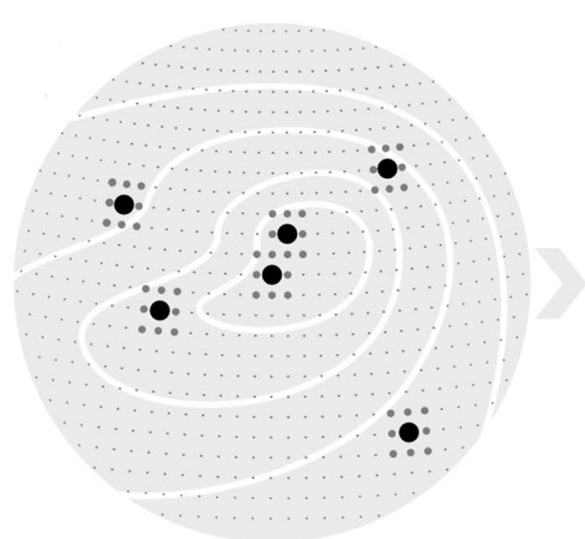

Local minimums at $0.25^{\circ} \times 0.25^{\circ}$ grid

Geopotential Height at $1000 \mathrm{hPa}\left(\mathrm{Z}_{1000}\right)$ b NEARBY CANDIDATES FILTER

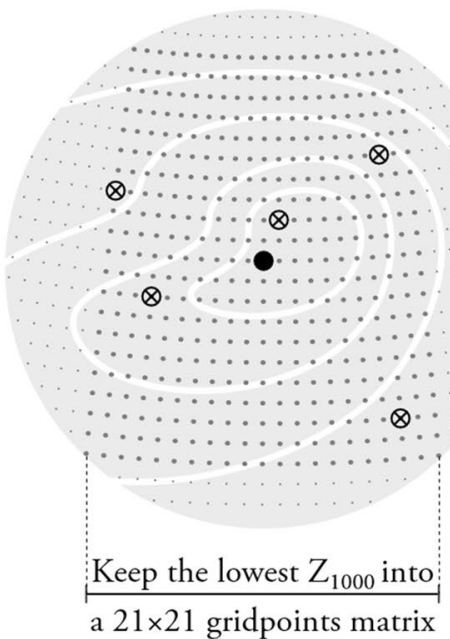

c

\section{DIRECTIONAL GRADIENTS FILTER}

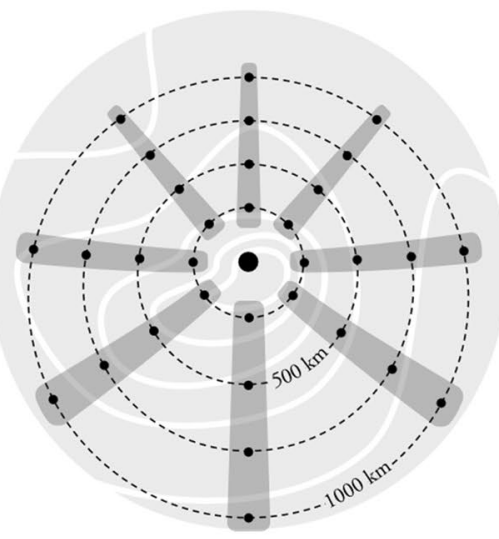

Depression verified on

a Rossby-deformation scale

Fig. 2 Cyclone identification module applied to each timestep present in the ERA5 dataset 
CycID, Fig. 2b). In general, this threshold allows a cyclone velocity slightly higher than those employed by current CDTM. But, considering the increased temporal resolution of ERA5 dataset, it also works to avoid other candidates within the same low-pressure core area.

As the timestep advances, the combined candidate positions trace a route that, in turn, ends when it is not possible to find a candidate at $t_{n+1}$ inside the search box of the candidate at $t_{n}$, concluding the cyclone lifecycle. Following Trigo et al. (1999), every time that candidates can be combined for at least six consecutive timesteps, we have a new cyclone included to the main product of this CDTM, the cyclone tracking dataset. To prevent cyclone tracks identified into the $6^{\circ}$ belt of surrounding the MR (Fig. 1), every cyclone without at least one position recorded within the MR limits was excluded. Additionally, trying to eliminate artificial low-pressure cores, short-living thermal-lows or too weak cyclones as much as possible, the present study only considered cyclones lasting more than $24 \mathrm{~h}$. This procedure also permits a further comparison with other literature results (Neu et al. 2013; Lionello et al. 2016).

It is worth mentioning that the criteria and thresholds established on CycID and CycTR modules were verified through a subjective analysis carried out for two random winter (January 1979 and 2005) and summer months (July 1991 and 2018). Several MR cyclones were identified and tracked individually, whether short or long durations and covering various parts of the domain. These analyses revealed that the proposed CDTM is capable to capture almost the totality of the observed cyclones, as well as describing its respective area of cyclogenesis, trajectories, and durations. More than an adaptation to a high-resolution dataset, the method described in the present study brings as its primary contribution a suitable set of parameters to systematically identify and track the cyclonic activities in the Mediterranean, where cyclones do not have sizeable horizontal pressure gradients and present a shorter lifetime compared to open-ocean cyclones.

The algorithm was developed in Wolfram Mathematica, v12.1, and uses the ERA5 dataset in NetCDF format. The output file presents for each identified cyclone and for each hourly timestep between cyclogenesis and cyclolysis: (1) the geographic coordinates (latitude, ${ }^{\circ} \mathrm{N}$, and longitude, ${ }^{\circ} \mathrm{E}$ ) of the cyclone centre position, (2) its intensity expressed in Geopotential Height at $1000 \mathrm{hPa}(\mathrm{m})$, and (3) the cyclone velocity $\left(\mathrm{km} \mathrm{h}^{-1}\right)$. Additionally, based on the geographic coordinates present in these outputs, (4) mean sea-level pressure (MSLP) values were also extracted from ERA5 to complement our analysis. Note that this procedure can be easily expanded to other parameters such as temperature, precipitation, and wind to evaluate other cyclones features, not assessed in the present study.
The CDTM presented in this study was designed to combine computational simplicity with generality on identifying cyclones to enable a study based on a recent released high-resolution reanalysis dataset, until now missing in the scientific literature. This simplicity-oriented approach does not allow detailed cyclone structure characterisations as core symmetry, vertical inclination, layer thickness, as well as temperature, precipitation, and wind distributions. However, combining the literature results with simple characteristics as cyclogenesis area, season, and duration, it is possible to associate certain cyclonic activities to well-known structures (such as low-thermal or extratropical cyclones) in a general context and without individualising each case.

\subsection{Impact of higher resolution to CDTM performances}

Given the significant spatial and temporal resolution improvements in the input dataset and its importance to CDTMs skills, not yet evaluated with such a volume of data, it is necessary to include among the objectives of this study a series of trials to assess the sensitivity of the CDTM algorithms to the increased resolution. For this purpose, the CDTM proposed by Trigo et al. (1999) was implemented following the adaptation of Lionello et al. (2016) and initialised with ERA5 data. Four settings of CDMT were created to operate on different data resolution (spatial and temporal). The principal modification regards the searching box employed in each stage. Lower resolution datasets were generated by subsampling the original ERA5 dataset, taking one set every $6 \mathrm{~h}$ at synoptic hours $(00,06,12$, and 18 UTC) to reduce the temporal resolution, and one gridpoint out of eight to reduce the spatial resolution. It is worth mentioning that preliminary tests using the preceding ReAnalysis dataset, ERA-Interim (Dee et al. 2011), indicated substantial differences between the number of identified cyclones. Therefore, we chose to subsample the ERA5 dataset to avoid errors associated with the initial data.

Table 1 summarises the strategy to assess the impact of high-resolution data on CDTMs, where four scenarios are

Table 1 Relevant parameters setting for the sensitivity tests

\begin{tabular}{lllllc}
\hline Scenario & \multicolumn{2}{l}{ Data resolution } & & \multicolumn{2}{l}{ CDTM analysis } \\
\cline { 2 - 3 } \cline { 5 - 6 } & $\begin{array}{l}\text { Space } \\
\left({ }^{\circ}\right)\end{array}$ & $\begin{array}{l}\text { Time } \\
(\mathrm{h})\end{array}$ & & $\begin{array}{l}\text { Box side } \\
\left({ }^{\circ}\right)\end{array}$ & $\begin{array}{l}\text { Matrix } \\
\text { (Gridpoints) }\end{array}$ \\
\hline LR & 1.50 & 6 & & 3.00 & $3 \times 3$ \\
iSR & 0.25 & 6 & & 3.00 & $13 \times 13$ \\
iTR & 1.50 & 1 & & 3.00 & $3 \times 3$ \\
HR & 0.25 & 1 & & 3.00 & $13 \times 13$ \\
FR & 0.25 & 1 & & 5.00 & $21 \times 21$ \\
\hline
\end{tabular}


defined: Low-Resolution (LR), incremented Spatial Resolution (iSR), incremented Temporal Resolution (iTR) and High-Resolution (HR). The CDTM proposed in the present study (Full Resolution, FR) was not used in this sensitivity test, but it was included in Table 1 only to make the comparison clearer. For uniformity reasons, the Directional Gradients Filter presented in Fig. 2c was maintained for all scenarios.

\section{CDTM performances using high-resolution data}

\subsection{Sensitivity test to improved resolution}

The annual cycle of cyclones frequency crossing MR during 1979-2018 is presented in Fig. 3 for different CDTM (Table 1). Conceptually, the LR scenario was designed to represent the current view about cyclonic development in $\mathrm{MR}$, and the HR scenario to reveal the improvement promoted by initialisation using enhanced datasets. On the other hand, the iSR and iTR scenarios were designed to assess spatial and temporal high-resolution contributions separately. In Fig. 3, the mean monthly distributions for the different scenarios are reported, showing small differences between the LR and HR scenarios' distributions, where the latter presented a mean number of cyclones approximately $10 \%$ higher, a value relatively low given the different volumes of data used. Both scenarios agree on the highest number of cyclones occurring in May-June followed by a secondary peak in August. The most prominent disagreements occur during winter months when the Low-Resolution scenario was not able to identify around $30 \%$ of the cyclones found by HR. In a quantitative assessment, there is a more significant variation in HR results, especially during winter months when the scenarios mostly disagreed. For July, both scenarios pointed to a reduction in the number of cyclones with smaller variation in HR but a large range between these absolute values.Although LR uses the ERA5 dataset subsampled for providing the same spatiotemporal resolution of ERA-Interim, the iTR was the scenario which presented the monthly variation of the number of cyclones (Fig. 3d)
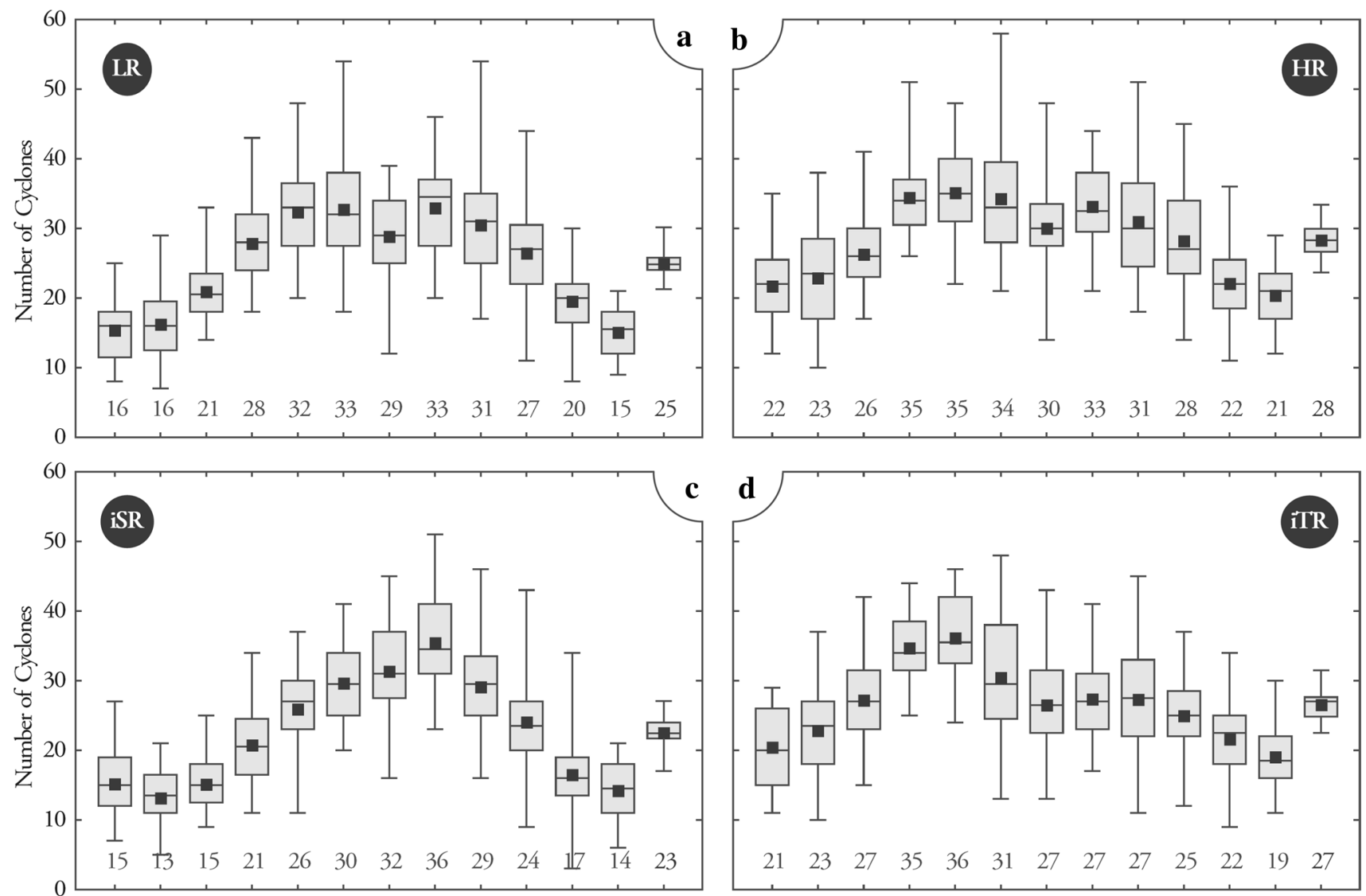

Jan Feb Mar Apr May Jun Jul Aug Sep Oct Nov Dec Mean

Fig. 3 Monthly means of the total number of cyclones in the Mediterranean Region (filled squares and bottom numbers), the respective 1 st, 2nd and 3rd quartiles (bars) and the absolute minimum and maxi-

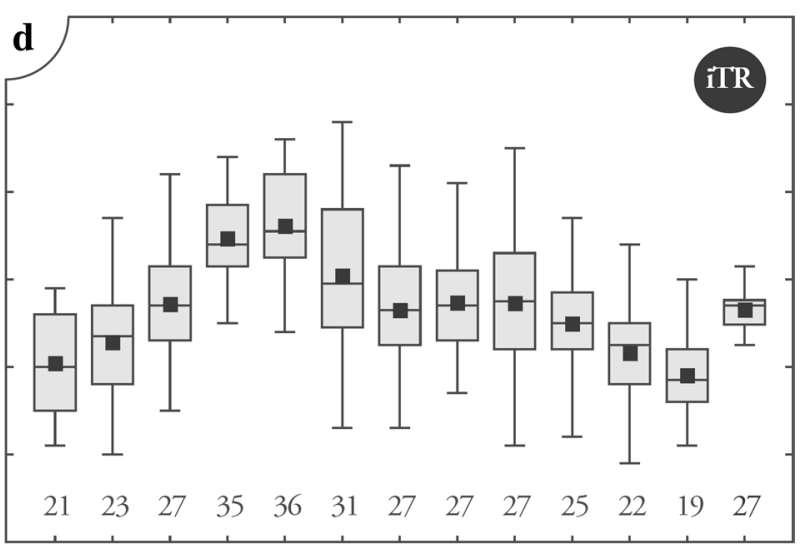

Jan Feb Mar Apr May Jun Jul Aug Sep Oct Nov Dec Mean

mum (dashes) illustrated as a box plot for different scenarios to the period 1979-2018 
more coherent to Lionello et al. (2016)'s results, where the monthly distribution also showed a maximum occurring during spring, a smooth variation on other months and no secondary peak in August. This result is relevant since Lionello et al. (2016) evaluated 14 different CDTMs applied to ERA-Interim (similar to LR) and none of these members was able to identify the rise on the cyclones number of August using low-resolution data. For the iSR scenario (Fig. 3c), the reduction in the total number of cyclones is even more evident, highlighting a very pronounced maximum occurring exactly in August.

A closer inspection of the dataset shows that the increase in the number of cyclones in August is due to a pronounced peak of cyclogenesis occurring near both zonal edges of MR: over the Iberian Peninsula as a consequence of relatively warm land, sea-land contrasts, and the formation of thermal lows (Trigo et al. 1999); and over the eastern Black Sea, where sea-land contrasts allied to low-level baroclinicity favour the formation and maintenance of quasi-stationary lows (Hoskins and Valdes 1990). A remarkable feature of cyclones formed in August over these regions is the short lifetime and slow propagation, framing these systems on a sub-synoptic scale hardly reproduced into low-resolution atmospheric data.

The impact of increased resolution becomes visible when the analysis considers the dynamical features. Figure 4 shows the frequency distributions of duration and mean velocity of the detected cyclones for the four scenarios. The iSR scenario (Fig. 4c) identified about $77 \%$ of cyclones with mean velocities between 8 and $20 \mathrm{~km} \mathrm{~h}^{-1}, 63 \%$ lasting 24 or $30 \mathrm{~h}$, and only less than $5 \%$ last more than $60 \mathrm{~h}$. These values are substantially different from those reported for MR, with a velocity peak between 24 and $32 \mathrm{~km} \mathrm{~h}^{-1}$ and durations of about $42 \mathrm{~h}$ (Trigo 2006; Lionello et al. 2016). On the other hand, the iTR scenario (Fig. 4d) spreads both duration and mean velocity distributions over more comprehensive ranges. Also, the quartiles (Q1, Q2 and Q3) were similar to LR and HR. The duration's 98 th percentile reaches $88 \mathrm{~h}$. The mean velocity distribution has a wide peak around $30 \mathrm{~km} \mathrm{~h}^{-1}$ with not negligible fractions of nearly stationary (less than $20 \mathrm{~km} \mathrm{~h}^{-1}$ ) and very fast systems (above $60 \mathrm{~km} \mathrm{~h}^{-1}$ ). The HR scenario (Fig. 4b) shows similar shapes for the duration distribution. In contrast, the mean velocity distribution is rather similar to the iTR scenario, indicating that increases
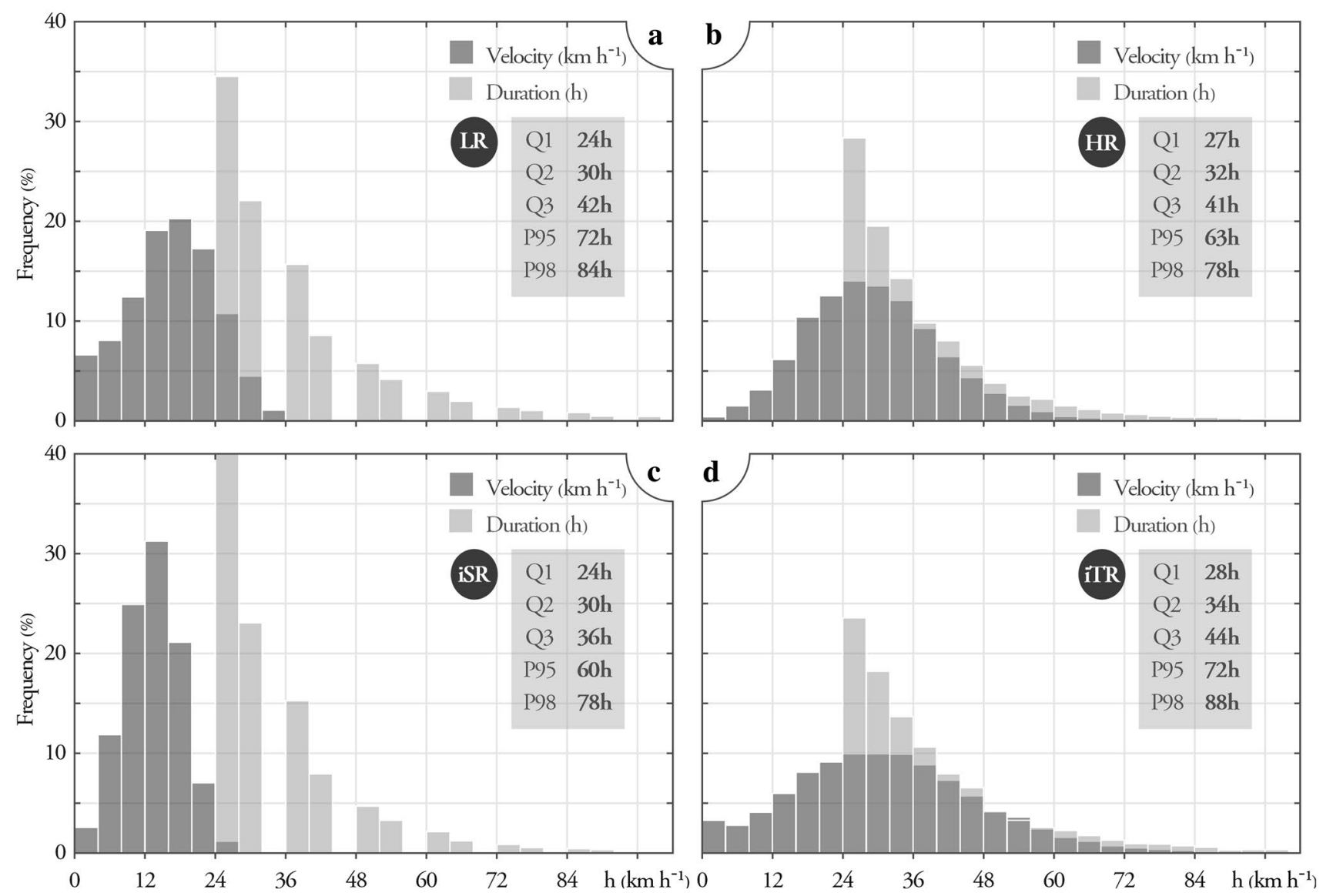

Fig. 4 Frequency distribution (\%) of cyclones mean velocity (black) and duration (gray) for different scenarios to the period 1979-2018. The 1st, 2nd and 3rd quartiles to cyclones duration are presented followed by the extreme percentiles (95th and 98th) 
on the time resolution must be balanced with increases on the spatial resolution to obtain results compatible with previous findings.

\subsection{CDTM tuning}

As shown in Fig. 3 and even more clearly in Fig. 4, the use of high-resolution data by existing CDTM (the HR scenario) presented sharp differences to the LR scenario, especially in the representation of long-duration cyclones. Since the search box size of each CDTM was crucial to achieving these results, a subjective analysis of cyclones trajectories was performed to understand how this parameter could be used to exploit the high-resolution available at ERA5 fully. The HR scenario tuning led to a modification of the search box sizes based at the Rossby-deformation scale, as indicated in Table 1, to develop a new CDTM (FR) used from here and on.

Figure 5 presents the mean monthly number of cyclones crossing the MR into 1979-2018 period and the distributions of cyclone duration and mean velocity for the FR scenario, computed by the CDTM proposed in this work with the high-resolution ERA5 dataset. Again, there is a large number of cyclones occurring during the spring months. April and May recorded the highest cyclogenetic activity in the MR with respective averages about 35 and 36 cyclones per month, reaching values around $40 \%$ above those described in the literature (Lionello et al. 2016).

As LR and HR, the FR scenario (Fig. 5a) also shows a secondary maximum in August, opposing a downward trend evidenced in June and July. In the following months, the distribution retrieves the downward trend, gradually decreasing the mean monthly number of cyclones as winter approaches. The mean monthly number of cyclones crossing the MR was 28, projecting 336 cyclones per year, equal to the HR scenario but with lower interannual variability and relatively lower spread, confirming the robustness of the proposed CDTM with high-resolution data. Again, this value is $40 \%$ above those estimated by CDTMs based on low-resolution data, but within the range described in the literature, 62 to 474 cyclones year (Lionello et al. 2016). The entire 1979-2018 period amounts 13,439 cyclones identified, composed of annual totals ranging from 285 up to 390 cyclones per year, respectively in 1990 and 2010.

Regarding the mean velocity and duration of the Mediterranean cyclones (Fig. 5b), the FR scenario presents distributions similar to HR. However, FR shows a flat peak around $11 \%$ in the frequency of cyclones with mean velocities between 32 and $36 \mathrm{~km} \mathrm{~h}^{-1}$, versus a more pronounced peak of $14 \%$ for velocities between 24 and $28 \mathrm{~km} \mathrm{~h}^{-1}$ obtained by HR (Fig. 4b). The same occurs in the cyclone duration distribution, where FR also presents a peak with frequencies smaller than those reported by HR, supporting the remarkable variation on cyclone durations and setting the quartiles over longer durations. This result confirms the improvement obtained by the new CDTM designed to use high-resolution data since the HR results showed a CDTM prone to underestimate cyclone's lifetime. In this case, evaluating the number of cyclones with long duration, the P95 and P98 show values in agreement with Trigo (2006) and the LR scenario, which uses a CDTM suitable to low-resolution data.

\subsection{Case studies}

As previously mentioned, the demand for a new CDTM suitable for high-resolution data emerged during several subjective analyses carried out for four random monthly periods, where the current CDTMs (the LR and HR scenarios) presented certain limitations to identify, track, and describe the main features of the observed cyclones. Therefore, this section presents the analysis of two prominent cyclones comparing the CDTM performances directly through the
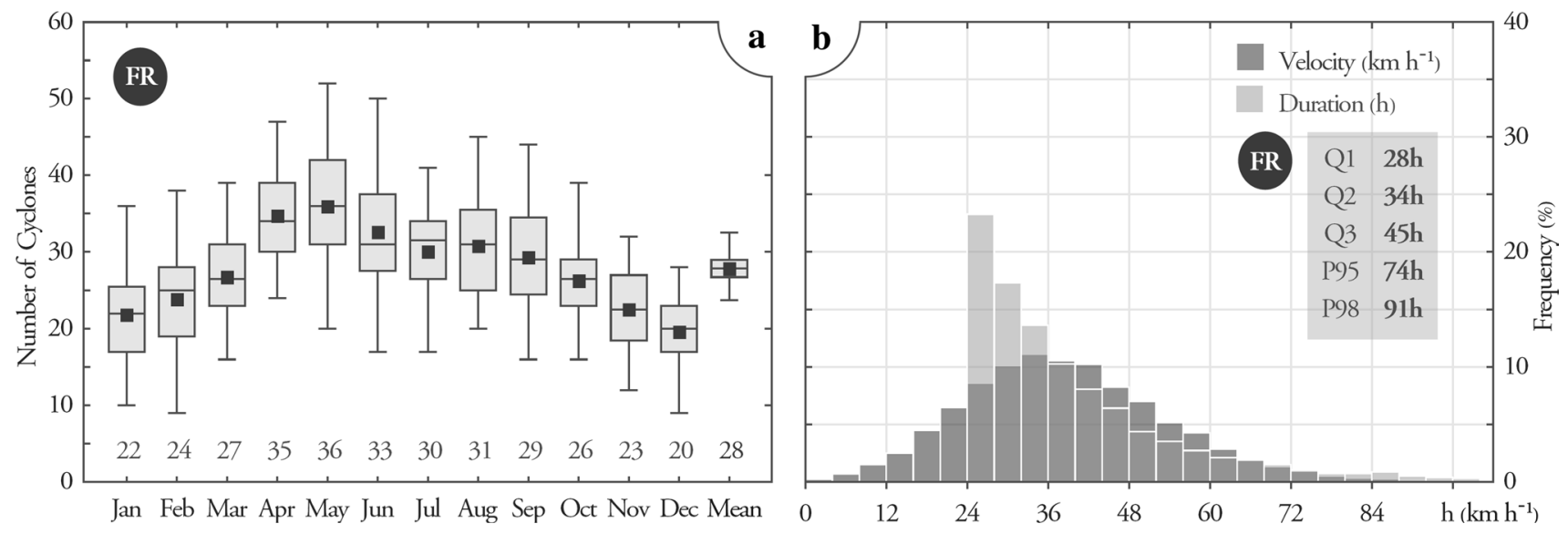

Fig. 5 Same as Figs. 3a and 4b, but for scenario FR using the CDTM proposed in the present study 
LR, HR and FR scenarios. The first one occurred in January 2009, when an intense cyclone crossed almost the whole MR resulting in one of the most extended cyclone trajectories in the 1979-2018 period. The second case portrays the Mediterranean tropical-like cyclone (also known as Medicane) Numa occurred in November 2017, which caused strong winds and large amounts of precipitation in southern Italy and several sites surrounding the Ionian Sea. These cases were selected based on previous studies of Liberato et al. (2011) and Marra et al. (2019), respectively.

The cyclogenesis pattern of the first case is the most common one in MR cyclones, where the Enhanced Rossby wave breaking associated to North Atlantic cyclones leads to an increase of the upper-level jet speed and a decrease in low-level stability, favouring new cyclogenesis zones in this region of anomalously low stability along the European continent (Buzzi and Tibaldi 1978; Hanley and Caballero 2012). In this case study, the Rossby wave's deceleration after entering the European continent resulted in two relevant cyclones on surface levels. The first was called 'storm Klaus' (Liberato et al. 2011) and started at 22 January 2009 over the subtropical North Atlantic Ocean, reached its maximum intensity at the end of 23 over the Bay of Biscay and, as advanced into the European continent, lost strength and vanished on 27 approaching to the Balkan Mountains. As the cyclogenesis and most storm Klaus track happened outside our study domain, only the final stage was described in our results explaining the small differences between the scenarios used (not shown here).

The second meteo-system driven by the propagation of the Rossby wave emerges on 25 January 2009 in the lee of Pyrenees Mountain range, at which time the storm Klaus was heading for cyclolysis over the Adriatic Sea. Figure 6 shows the cyclone track's places and dates, and the respective system intensity evolution assessed under the LR, HR and FR scenarios. In general, excluding the resolution limitations of the LR scenario during the initial period, all scenarios agree with the cyclogenesis location, date and time, and the main track performed by the cyclone during its existence. However, there is a significant divergence regarding the cyclone duration and its cyclolysis region.

In this case, a subjective analysis including other parameters, such as the mean sea level pressure (MSLP) and the geopotential height at $500 \mathrm{hPa}$, confirmed the FR scenario as the best description of the cyclone's life cycle: (1) starting at $15 \mathrm{Z}$ on the 25 ; (2) reaching maximum intensity on 26 (12Z) between Corsica and Sardinia ( $991 \mathrm{hPa}$, see the embedded graph in Fig. 6); (3) losing strength as it approaches southern Italy at the end of day 28; (4) moving eastward nearly unchanged, passing through the Ionian and Aegean seas; and (5) vanishing in the eastern Mediterranean, nearby Cyprus. In summary, more than $3068 \mathrm{~km}$ were covered in $144 \mathrm{~h}(6$ days) with mean velocity about $21.3 \mathrm{~km} \mathrm{~h}^{-1}$ and a maximum deepening of $0.75 \mathrm{hPa} \mathrm{h}^{-1}$ and $1.57 \mathrm{hPa} 6 \mathrm{~h}^{-1}$. These values of track length and durations are extremely rare in the MR, totalising less than $0.12 \%$ of cyclones within $1979-2018$ period.

As shown in Fig. 6, the LR and HR scenarios were able to reproduce only the whole cyclone track's initial phase. The cyclone weakening after crossing Sicily Island, in southern Italy, prevented the LR and HR CDTMs from identifying possible candidates over the Ionian Sea, interrupting the life cycle prematurely on days 29 (06Z) and 28 (18Z), respectively. However, in this initial phase, both LR and HR scenarios presented cyclone track, mean velocities and core MSLP very similar to FR (LR $19.6 \mathrm{~km} \mathrm{~h}^{-1}$ and HR $16.3 \mathrm{~km}$ $\left.\mathrm{h}^{-1}\right)$. Interestingly, $30 \mathrm{~h}$ after ending the cyclone's activities under analysis, the HR scenario identified a new cyclone

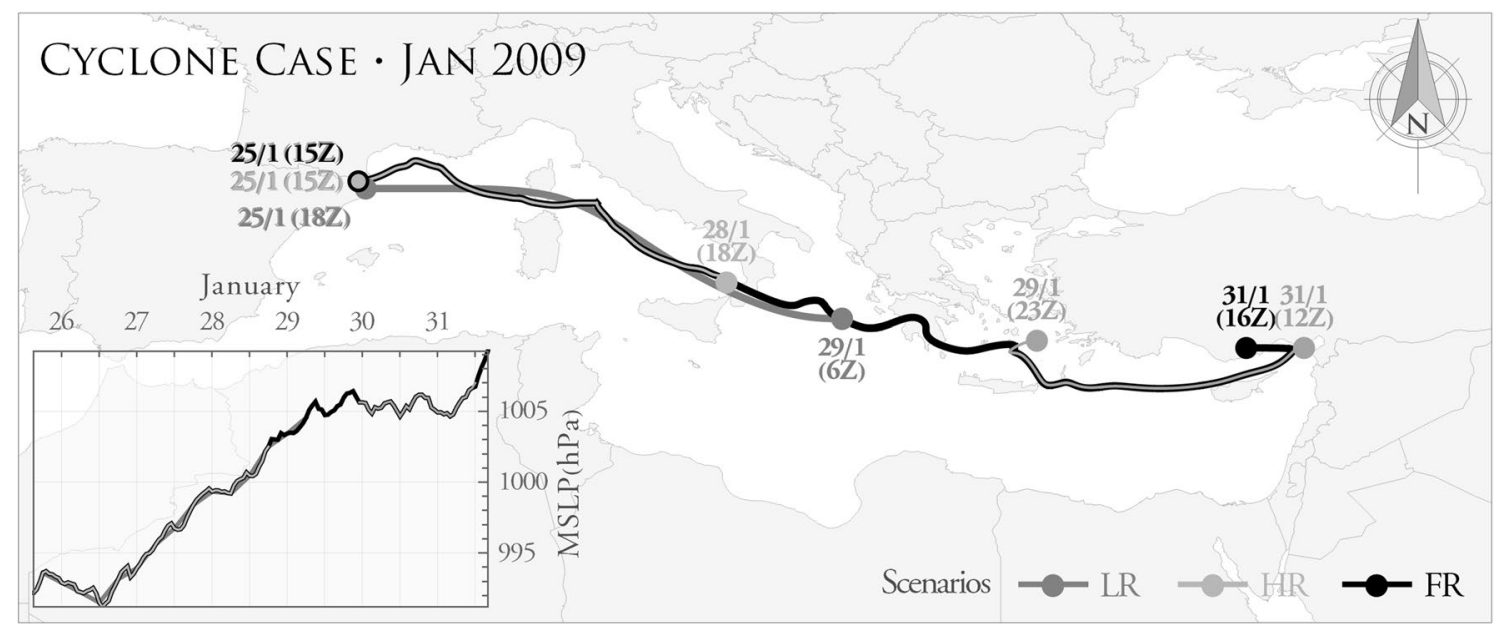

Fig. 6 Tracking comparison of the cyclone occurred on 25-31 January 2009 using the LR (gray), HR (light gray) and FR (black) scenarios. The Mean Sea Level Pressure (MSLP, hPa) during the entire life cycle is shown in the embedded graph 
forming over the Aegean Sea, which followed the characteristics of the previous one described in the FR scenario. This result confirms the hypothesis raised in the monthly subjective analyses, where a CDTM not tuned for using high-resolution data (HR) tend to identify long-duration cyclones as two or more different cyclones, and also explains the increase of cyclones duration percentiles 95 and 98 in the FR scenario (Fig. 5a).

The second case shown in detail was the Medicane Numa occurred in November 2017. As synoptic-scale cyclones, Medicanes can also be defined as low-pressure systems formed in MR and supported by a cold trough at upper-air levels. The main difference is its baroclinic nature which, in the mature stage, presents a warm core due to the release of latent heat by convection around the system centre (Cavicchia et al. 2014). By definition, there are no limitations that prevent the detection of Medicanes using CDTM. On the contrary, as these meteorological systems usually present a well-defined symmetric structure with a centre equally surrounded by intense gradients, the potential for identification and characterisation is very high.

According to Marra et al. (2019), the Medicane Numa started on 15 November over the Strait of Sicily, reaching its mature phase on the next day, where it persisted for $24 \mathrm{~h}$ with a quasi-cloud-free calm eye, a warm core, and strong winds close to the vortex centre. On day 18 , it moved eastward until completely dissipates over Greece on 19 November. As shown in Fig. 7, the LR scenario is the most similar to this description in terms of date and location of the cyclogenesis and cyclolysis zones. An expected result, considering that Marra et al. (2019) conducted an analysis based on satellite images and weather forecast model products with low-resolution $\left(1.125^{\circ}, 3 \mathrm{~h}\right)$.

On the other hand, differently from LR, the high-resolution scenarios (HR and FR) presented identical results, showing that the high-resolution was more decisive than CDTM tuning for the Medicane case. The main difference was the initial and final moments of Numa's life cycle, where high-resolution scenarios indicated cyclogenesis occurring $7-8 \mathrm{~h}$ before, close to the Italian coast. The estimated cyclolysis occurs 16-19 $\mathrm{h}$ after LR, extending the cyclone tracks from the Greek coast in the Ionian Sea to the Turkish coast in the Aegean. Another significant improvement provided by the high-resolution data is the temporal evolution of MSLP in the centre of the Medicane (embedded graph in Fig. 7). The slow displacement of Numa allows observing in detail the semidiurnal barometric oscillation also influencing the meteo-system core.

\section{Mediterranean cyclones climatology}

\subsection{Regional distributions}

This section exploits the FR scenario's capabilities in describing the climatology of Mediterranean cyclones, addressing seasonal and geographical distributions of cyclogenesis/cyclolysis areas, and the main characteristics of the detected systems. Using the proposed CDTM at ERA5 resolutions, Fig. 8 presents the spatial distribution of (a) the frequency of cyclogenesis, (b) the frequency of cyclone tracks, (c) the cyclones maximum velocity, and (d) the maximum cyclones deepening rate (minimum MSLP variation over $6 \mathrm{~h}$ ). For presentation purposes, these maps use a radial signal amplification technique to minimise the high-resolution dataset's noise and avoid large values variation at neighbour gridpoints. The frequency of cyclogenesis is reported as the fraction of the total number of cyclones born at the gridpoint position by the total number of cyclones born in the whole MR. The same works for the frequency of cyclone tracks but

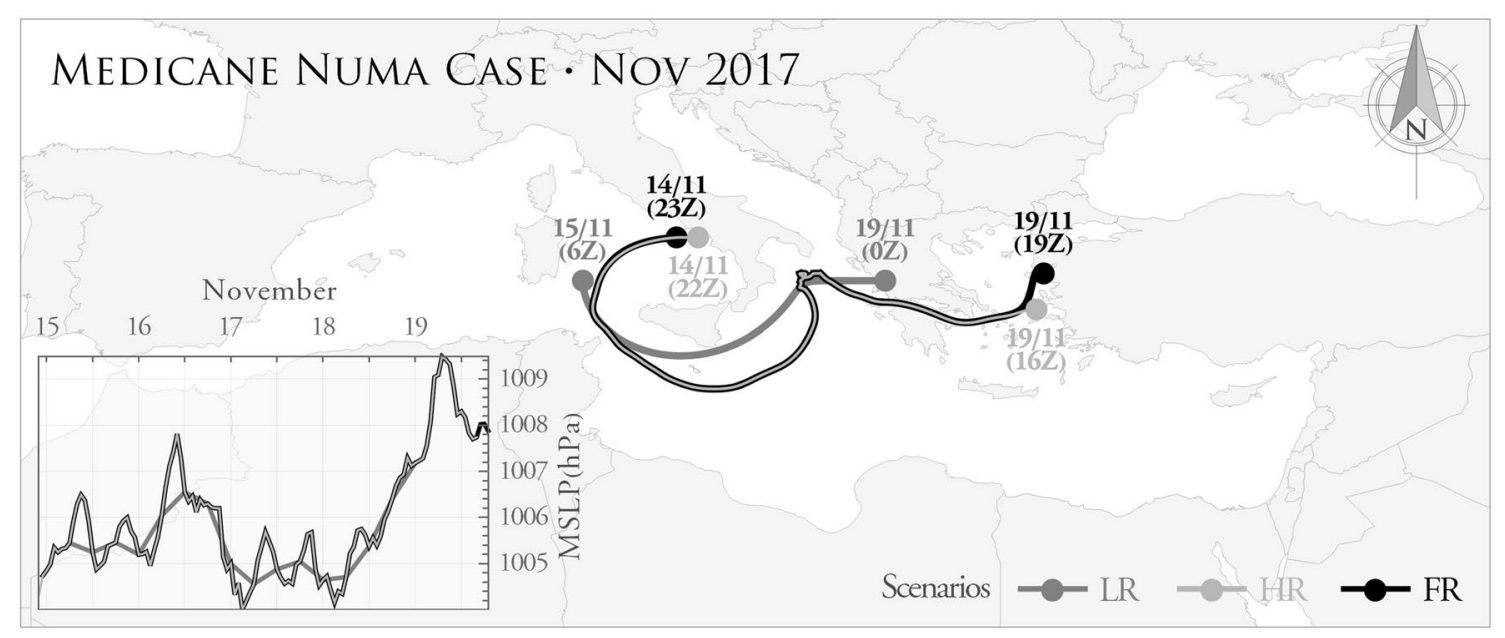

Fig. 7 Same of Fig. 6, but for the Medicane Numa occurred on 14-19 November 2017 


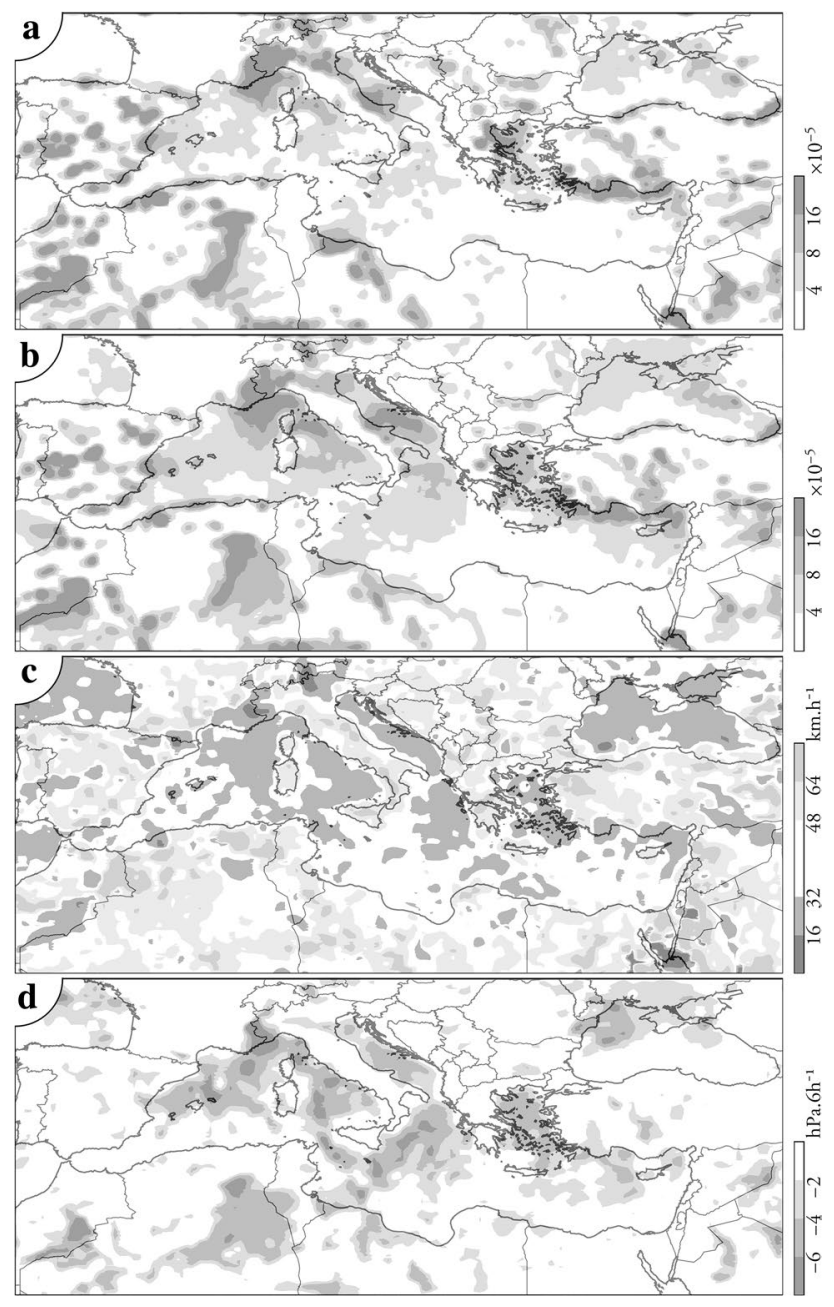

Fig. 8 Spatial distribution of MR cyclones: a frequency of cyclogenesis (\%); $\mathbf{b}$ frequency of cyclones tracks (\%); c cyclones' mean velocity $\left(\mathrm{km} \mathrm{h}^{-1}\right)$; and $\mathbf{d}$ cyclones' maximum deepening rate $\left(\mathrm{hPa} 6 \mathrm{~h}^{-1}\right)$

considering a fraction of the cyclone path instead of cyclogenesis number. Lastly, the cyclones' mean velocity and the cyclones' maximum deepening rate $\left(d P_{\min } / d t\right)$ report the averaged parameter concerning every cyclone crossing the gridpoint position.

As shown in Fig. 8a, MR presents several regions prone to cyclones' formation, most of them directly related to mountain ranges and coastlines. The main cyclogenesis areas have been accurately identified, with intensities and activity areas relatively similar to those found in the literature (Trigo et al. 1999; Trigo 2006; Campins et al. 2011; Lionello et al. 2016). About $89.1 \%$ of the identified cyclones in the whole study domain presented cyclogenesis inside the MR. Positioned in the lee of the Alps, the Gulf of Genoa appears as the primary hotspot of cyclone formation in the MR (Buzzi and Tibaldi 1978), assuming 11.3\% of this total. In sequence, there are areas of intense cyclogenetic activity over the western (8.9\%) and eastern Atlas Mountains
(6.5\%), along the southern coasts of Antalya (5.8\%), around the Balearic Islands (5.0\%), and over the northern Aegean Sea $(4.1 \%)$. The percentage was computed considering areas of $400 \mathrm{~m}^{2}$, approximately, centred at the main hotspots of cyclogenesis into the MR.

The accurate representation of the intense cyclogenetic activity areas using high-resolution data also enabled us to explore regions rarely regarded as principal cyclogenesis areas in MR. A good example is the Aegean Sea. As reported in the literature, the current available CDTMs often underestimate the cyclogenesis due to its subsynoptic-scale nature (Flocas and Karacostas 1996; Campins et al. 2011). In our analysis based on high-resolution data and the proposed CDTM, such distrust was overwhelmed by a proper detection of cyclones of the nature mentioned above and statistically framed the Aegean Sea among the principal areas of cyclogenesis of MR into an annual perspective.

On the other hand, areas usually reported with high cyclogenetic activity exhibited reduced signals, such as the Black Sea, the eastern Mediterranean, and Middle East areas. According to Trigo et al. (1999), these areas have a strong signal explained by the domain boundaries' vicinity. In fact, in a later study also using low-resolution data (Campins et al. 2011), this signal was not recognized among the largest cyclogenetic areas, even when analysed into a seasonal window. In the present study, the data resolution's improvement and the analysis domain's expansion (Fig. 1) confirmed to be sufficient to avoid border issues.

Another region highlighted by a significant cyclogenetic signal is the coastal area from southern Tunisia to western Libya (Fig. 8a). Although not properly identified in previous climatological studies, this region constantly records damages and losses caused by meteorological events, commonly associated to cyclones developed under particular conditions driven by a strong land-sea temperature contrast (Almazroui and Awad 2016). However, even if cyclogenesis occurs in this particular condition, the signal is strong enough to be noticed into an annual window, totalising $4.7 \%$ of the MR cyclones. It probably occurs with characteristics analogous to the Aegean Sea cyclones, where a subsynoptic-scale nature prevents a feasible signature on low-resolution data. Thus, the annual cycle, frequency and principal features of the Tunisia-Libya cyclones must be fully assessed in future works.

Other fields in Fig. 8 present a well-defined pattern in the entire study domain: cyclones tracks expand from the cyclogenesis areas (Fig. 8b), generally slower over the sea and the coastal regions, and faster around mountain ranges (Fig. 8c), and intensifying over the sea or when approaching to the coastline (Fig. 8d). For example, cyclones formed in the Gulf of Genoa usually moves along two branches: (1) southward over the Tyrrhenian Sea, moving slowly when closer to the Italian coast, or gain intensity crossing the sea 
heading to Sicily; or (2) eastwards to the Adriatic Sea where they usually lose strength facing the Balkan Mountains or move southward losing velocity and gaining intensity.

In general, the MR cyclones present complex trajectories with frequent direction changes, often related to the land/sea distribution and the presence of orography. This explains the various branches of tracks in Fig. $8 \mathrm{~b}$ associated with the departing regions. As shown in Fig. 9a, a large part of the analysed cyclones $(\sim 46 \%)$ used to travel between 800 and $1600 \mathrm{~km}$ into MR, while the distance between the cyclogenesis and cyclolysis positions (hereafter, CCDistance) does not exceed $800 \mathrm{~km}$ in the majority of cases $(\sim 76 \%)$. In these cases, only $16 \%$ of cyclones travel a track up to 1.5 distant from the departing position. The more frequent value for the track/CCDistance ratio (Fig. 9) is about $2.6(\mathrm{Q} 2)$ but ranges from 1.7 (Q1) up to $4.5(\mathrm{Q} 3)$. Curiously, cyclones associated with this ratio above 4.5 presented a mean velocity of $20.2 \mathrm{~km} \mathrm{~h}^{-1}$, remarking the stationary nature of these cyclones which are known to be more frequent along the Atlas Mountains, over the Iberian Peninsula and the Black Sea regions (Trigo et al. 1999; Campins et al. 2011).

Cyclones in the MR rarely reach intensities similar to typical storms in the northern Euro-Atlantic sector (Trigo 2006), presenting minimum MSLP between 1000 and $1008 \mathrm{hPa}$ (Fig. 10a). Although still a preliminary analysis, only 62 cases $(0.46 \%)$ registered with depths below $980 \mathrm{hPa}$, which, in a 40-year context, averages 1.6 cyclones per year with extreme intensity.

According to Fig. 8d, cyclones with the highest deepening rates presented tracks crossing over the Mediterranean Sea. Overland, mainly in western of MR, there are few branches of deepening associated with the stationary cyclone regions (Western and Eastern Atlas and the Iberian Peninsula). Although $64 \%$ of the hourly deepening rates vary from -0.8 to $-1.2 \mathrm{hPa} \mathrm{h}^{-1}$ (not shown), just a few cyclones can maintain this rate for a long period in the MR and accumulate
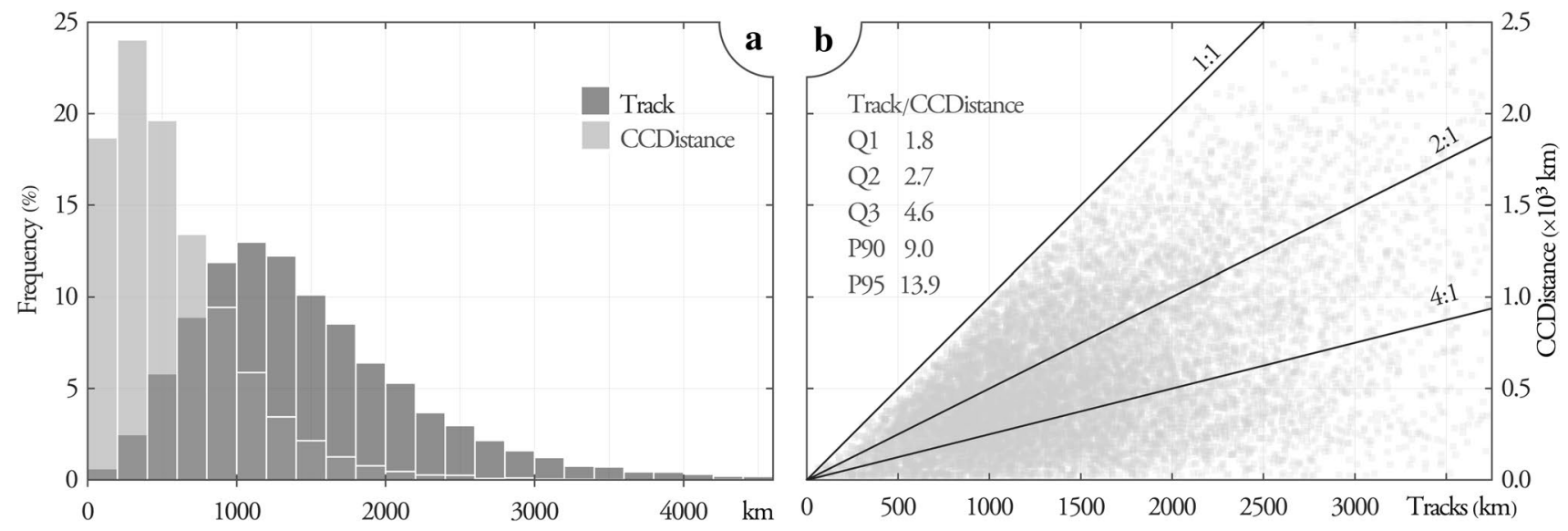

Fig. 9 Frequency distributions (a) and direct comparison (b) of the distance between cyclogenesis and cyclolysis positions (CCDistance) and total cyclone's track
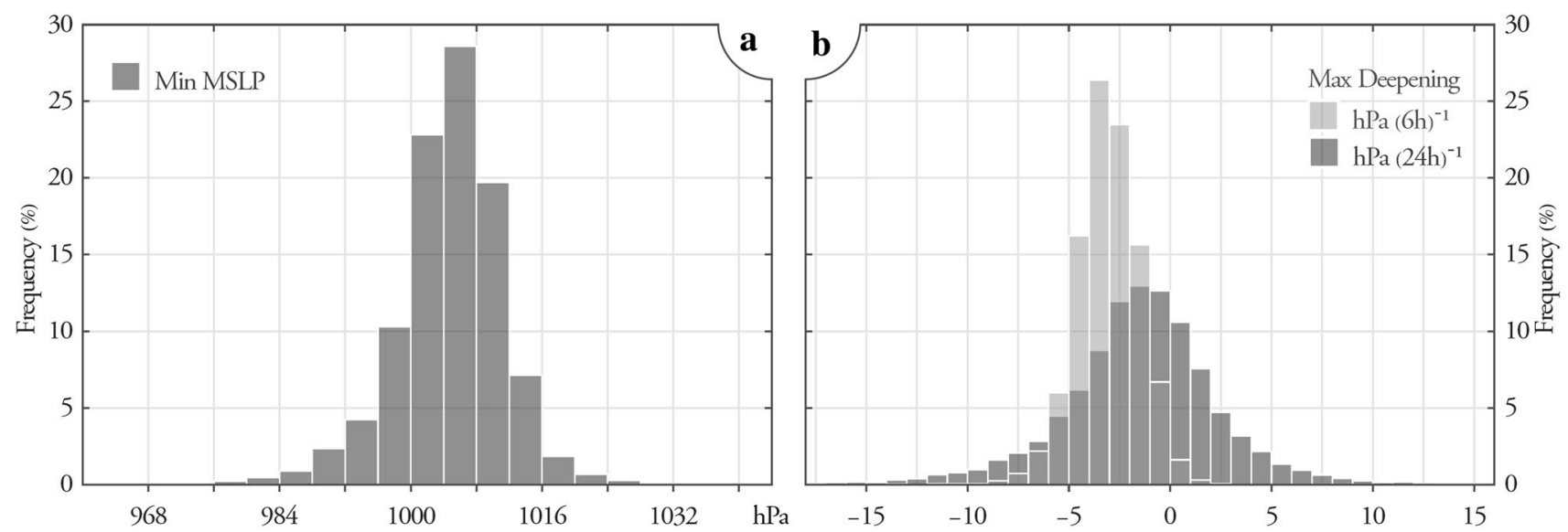

Fig. 10 a Minimum MSLP distribution (\%), and b maximum deepening rate distributions (\%), in $6 \mathrm{~h}$ (gray) and $24 \mathrm{~h}$ (black) 
$6 \mathrm{hPa}$ in $6 \mathrm{~h}$, or the threshold of $24 \mathrm{hPa}$ in $24 \mathrm{~h}$, defined by Sanders and Gyakum (1980) to be considered an explosive cyclone. A large part of cyclones, about $45-50 \%$, registered maximum deepening rates between -3 and $-4 \mathrm{hPa}\left(6 \mathrm{~h}^{-1}\right)$, and from 0 to $-4 \mathrm{hPa}\left(24 \mathrm{~h}^{-1}\right)$ (Fig. 10b).

The present study only recorded three explosive cyclones in MR among the 40 years analysed, while Trigo et al. (2006) found four explosive cyclones between 1958 and 2000 using a low-resolution reanalysis dataset (ERA-40). Despite being a predominantly oceanic phenomenon (Trigo 2006), it is possible to observe high deepening rates under extreme weather conditions even in closed and heterogeneous regions such as the MR.

\subsection{Seasonal analysis}

Among the main cyclogenesis areas in MR (Fig. 8a), only the Gulf of Genoa and Western Atlas Mountains presented a persistent and robust signal in all seasons (Fig. 11). The Aegean Sea and Cyprus areas also showed a persistent cyclogenetic activity but with spatial and frequency reductions during the spring, even considering the highest number of cyclogenesis of this season. The cyclogenetic activity reduction in the Cyprus area was the most significant, with its maximum during the winter (Fig. 11d) immediately followed by a minimum in spring (Fig. 11a).

In general, the warmer seasons (spring and summer) present a larger number of cyclones forming over the continent and along the coastlines, while in the colder seasons (autumn and winter), the cyclogenesis concentrates over the sea. Since spring and autumn are transitional seasons, these patterns are quite mixed during these months, while during winter and summer are clearer. The main seasonal variations are directly associated with a significant increase of cyclogenesis over the Iberian Peninsula and the Eastern Atlas Mountains during spring and summer. On the other hand, the increase in cyclogenetic activities over the Balearic, Ionian and eastern Mediterranean seas occurs during autumn and winter. Figure 11 also shows a persistent activity during all seasons along the coast of Tunisia and Libya, with the development of fewer cyclones in winter, increasing the frequency in the following months, and reaching its maximum during the autumn.

Figure 12 shows the density of cyclone tracks crossing the MR in the study period analysed from a seasonal perspective. As in Fig. 8b, the main branches of tracks depart from the cyclogenesis areas and spread according to the characteristics of the cyclone formed. In the Western Atlas, for example, there are tracks concentrated strictly along with the mountain range throughout the year, highlighting the cyclones' stationary nature of this region. Another region known for this nature is the Iberian Peninsula, where many tracks occur only in the central area due to the slow and short

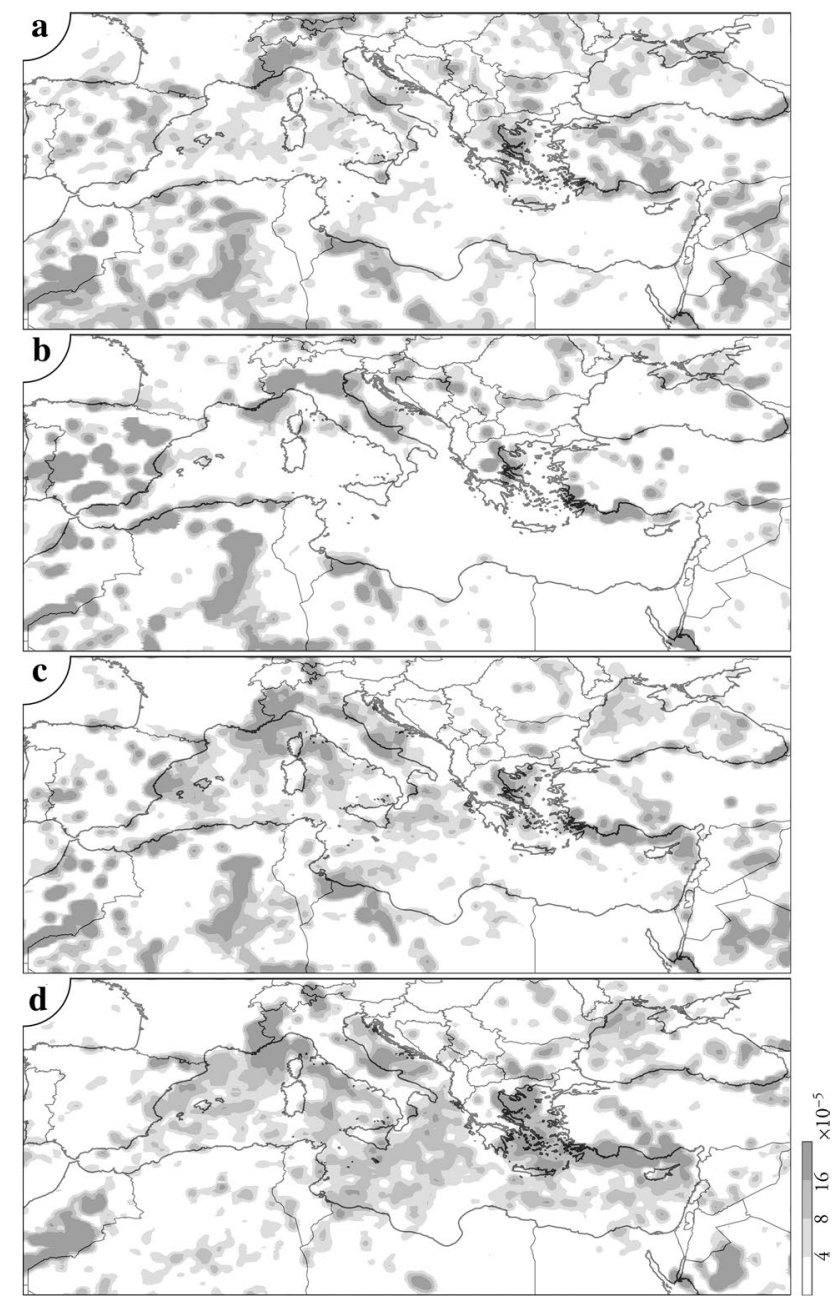

Fig. 11 Same of Fig. 8a, but considering seasonal windows: a spring MAM, b summer JJA, c autumn SON, and $\mathbf{d}$ winter DJF

displacement of thermal lows. In this case, as the cyclogenetic activity occurs in the summer (Fig. 11b), the cyclone tracks also presented the same trend.

There are two types of cyclones forming along the coastline of the Iberian Peninsula. The first is similar to cyclones found in the central area, with intense cyclogenetic activities only during the summer and short tracks associated with the thermal lows' stationary nature. The second is less frequent but observed most of the year (autumn, winter, and spring) when it presents a migratory pattern with tracks expanding eastwards across the Balearic Islands. The maximum of cyclogenesis occurs in autumn (Fig. 12c) when the tracks indicate a trend of movement towards the south of Sardinia. At the same time, during the spring the cyclonic paths are mainly directed to the northeast.

The land and sea pattern found in summer and winter cyclogenesis, respectively, is even more apparent when analysing the density of cyclone tracks. As shown in Fig. 12d, winter cyclones tend to form and transit over the central MR 


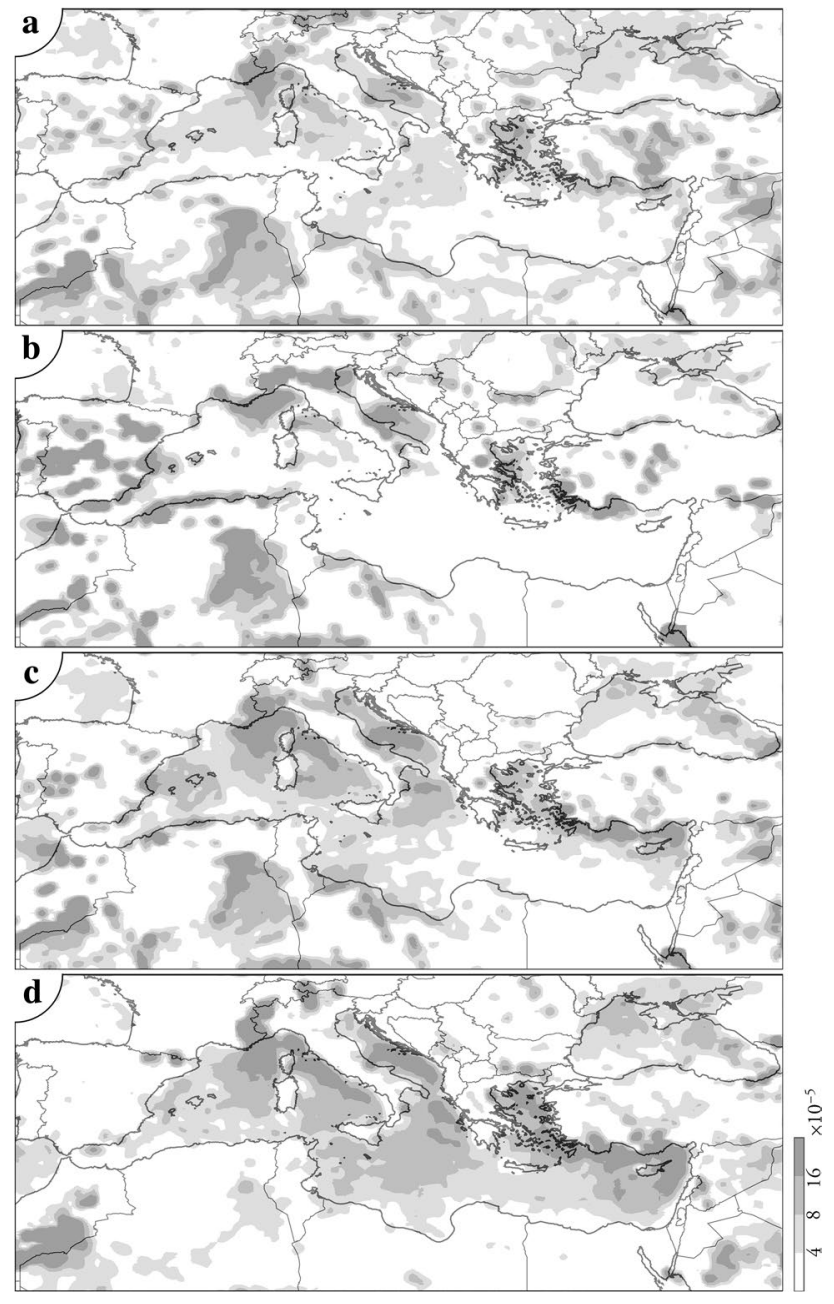

Fig. 12 Same of Fig. 8b, but considering seasonal windows: a spring MAM, b summer JJA, c autumn SON, and $\mathbf{d}$ winter DJF in the Tyrrhenian, Adriatic and Ionian seas. Additionally, there is a large number of cyclones forming in the Aegean Sea and Cyprus with trajectories mainly concentrated in the Eastern Mediterranean. For the cyclogenesis hotspot in the MR, the Gulf of Genoa, there is a peculiar seasonal variation in the tracks of cyclones formed in this region. Throughout the year, cyclones tend to move southward in branches that extend to the Ionian Sea and North Africa. However, during the summer, when cyclones present continental tracks (Fig. 12b), there is a significant increase of zonal tracks over the Boniface strait regions (between Sardinia and Corsica) and the Po valley in Northern Italy. As Bladé et al. (2012) commented, the large-scale control is essential in local summer convection triggering in the central Mediterranean. This explains the increase in cyclone passages over the Adriatic Sea, once this region does not present variation on cyclogenesis number over the year.

\subsection{Continuous multi-parameter analysis across the year}

An integrated analysis amongst the multiple components describing cyclones in the MR is shown in Fig. 13. The main target is to identify the possible relationships between these features outside the usually defined meteorological seasonal windows. The 7-days moving average of the number of cyclogenesis and the number of active cyclones (Fig. 13a) guide the annual variation suggesting three distinct cyclonic seasons in the MR: the cyclogenetic high season, the thermal lows season, and the deep lows season. The interaction through the analysed parameters exhibited well-defined homogeneous patterns, which emphasise these

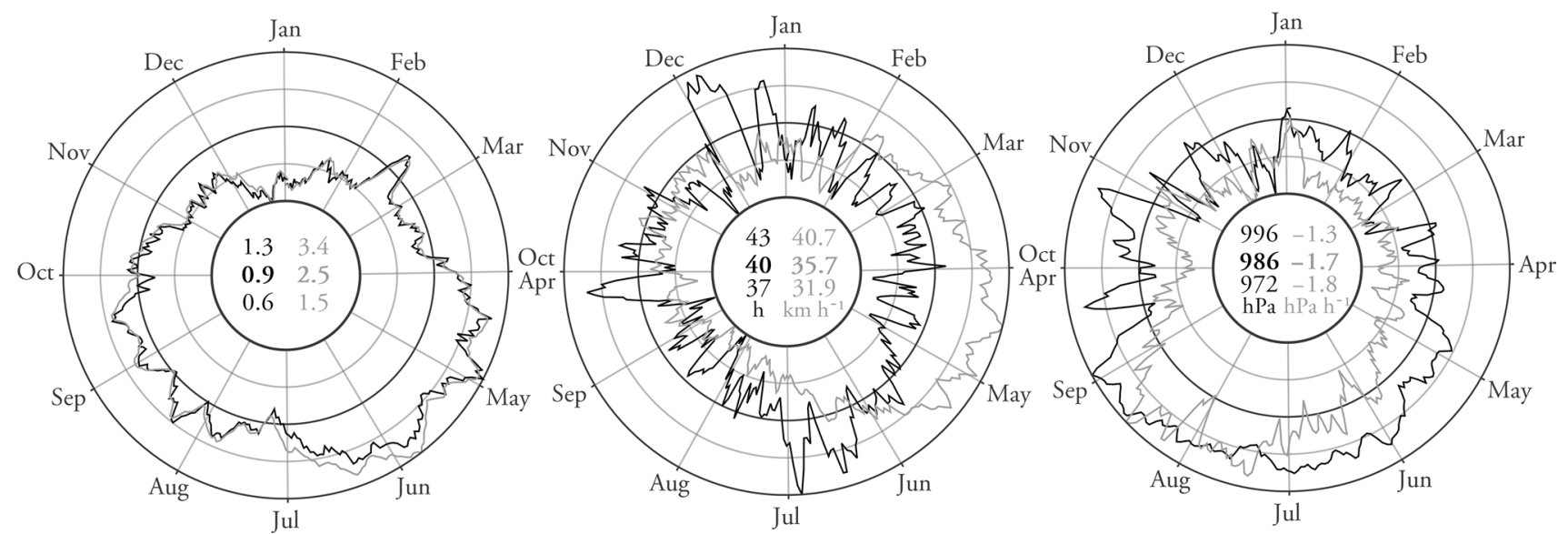

Fig. 13 The annual cycle of MR cyclone features described by 7-days moving averages from 1979 to 2018: a the number of cyclogenesis per day (black) and the number of active cyclones in the MR (gray); b the average duration of cyclones formed on each day (h, black) and the mean velocity of the active cyclones $\left(\mathrm{km} \mathrm{h}^{-1}\right.$, gray); $\mathbf{c}$ the minimum MSLP reached by the active cyclones (hPa, black) and the maximum deepening rate $\left(\mathrm{hPa} \mathrm{h}^{-1}\right.$, gray). The minimum, average and maximum values of each series are reported in the central circle and delimitate the radial axis range 
seasons' existence and allow the characterization of cyclones formed in each season.

The cyclogenetic high season begins when the daily cyclogenesis shows a significant increase and exceeds one cyclogenesis/day, starting in early April, and lasting until the 3rd week of June. The annual peak of daily cyclogenesis and active cyclones in the MR is reached during this period. In the first half (April to mid-May), cyclones present durations slightly shorter than average but also have the highest mean velocities (Fig. 13b) and high deepening rates (more negative values in Fig. 13c) of the year. These characteristics added by long tracks (Fig. 12) describe the extratropical cyclones pattern during the transition seasons (spring and autumn) governed by the intense equator-pole thermal gradient. In the second half, both parameters (mean velocity and deepening rate) lose intensity and compromise this season' cyclonic pattern, when the cyclones lifetime and the minimums of MSLP increase significantly. This is the only period of the year when the curves in Fig. 13a remain distant, indicating that the increase in the number of active cyclones occurs mainly by increases in duration and decreases in velocity.

After the end of the high cyclogenetic season, the number of active cyclones decreases until the first week of July (Fig. 13a). The following week until the first half of September, above average values are observed characterising the secondary cyclogenetic peak discussed in the statistical analysis (Fig. 5a). We label this period as the Thermal Lows season, marked by a number of cyclones slightly above the average, propagating slowly over short tracks (short duration, Fig. 13b), and without reaching significant depths (minimum MSLP in Fig. 13c). These features are commonly attributed to thermal lows formed during summer over the Iberian Peninsula and Eastern Atlas (Trigo et al. 1999; Lionello et al. 2016).

The cyclogenetic activities associated with thermal lows suddenly weaken in the early Autumn, when the Intertropical Convergence Zone starts to move southward and favours the entrance of cold air masses into the MR. As a result, cyclones begin to present more intense MLSP minimums, driven by higher deepening rates (Fig. 13c), breaking the cyclonic pattern of this period and ending the thermal lows season.

Starting from the 3rd week of September, cyclones present tracks over the sea, again (Fig. 12c) under conditions favourable to high deepening rates (Fig. 13c). This moment marks the beginning of the 3rd and last cyclone season: the Deep-Lows season is characterized by a smaller number of cyclogenesis but with more intense cyclones (lower MSLP minima, Fig. 13c). Far from being just a transition season from summer to winter, as suggested by Trigo et al. (1999), this season is marked by the return of migratory cold air masses to the still-warm waters of the Mediterranean Sea, producing cyclones with a lifecycle of unregular durations and mean velocities close to the annual average. On the other hand, the contrast of temperature also yields in cyclonic activities with the highest deepening rates and the lowest MSLP values, ranking this period as the most favourable to intense storms. These conditions last until early March when a significant increase in the mean velocity compromise the cyclonic pattern (Fig. 13b) and announces the transition period for the high season.

\section{Summary and conclusions}

A climatology of cyclonic activity throughout the Mediterranean Region over 40 years (1979-2018) is presented using the new high-resolution ECMWF reanalysis dataset, ERA5. A new Cyclone Detection and Tracking Method was developed and verified with subjective analysis and literature comparisons, to allow proper use of high-resolution data and a better description of systems on the subsynoptic-scale. The impact of high-resolution data on existing CDTM was evaluated considering different settings. The CDTM using low-resolution data presented the most similar results with the literature, showing the need to develop a new CDTM able to exploit the full potential of this new dataset.

The assessment of the impacts of increasing spatial and temporal resolutions revealed that increases in spatial resolution provide a better identification of cyclones developed in a subsynoptic-scale, usually underestimated by low-resolution data. On the other hand, increases in temporal resolution provide a better description of cyclone features, such as the location and time of cyclogenesis and cyclolysis, and the characteristic velocities and deepening rate.

Regarding the climatology of cyclones in the MR using the CDTM proposed in the present study, it was found a well-defined annual cycle of cyclonic activity with a maximum during spring and a minimum during winter, in complete agreement with the literature results. However, the use of a high-resolution dataset pointed to a secondary peak of cyclogenesis during the summer associated with an increase in the number of baroclinic driven lows over the continent, typical of this period, and which was constantly underestimated using low-resolution data.

In general, about 336 cyclones per year were identified in the MR. An amount $40 \%$ higher than the average of previous CDTMs, but within a coherent range found in other studies. This result was expected since the increase in resolution increases the number of possible identifiable cyclones. The cyclones presented durations of 24-36 h, mean velocities of $32-36 \mathrm{~km} \mathrm{~h}^{-1}$, minimum pressures about $1000-1008 \mathrm{hPa}$, and deepening rates between -0.8 and $-1.2 \mathrm{hPa} \mathrm{h}^{-1}$. The main findings in this topic were related to the detailed distributions of track length and deepening rates. First, the 
average distance between the cyclogenesis and cyclolysis positions showed values significantly below than the actual distance covered by cyclones. In this case, the morphological heterogeneity of the MR was the main responsible for the high track/CCDistance ratio, where the median showed values close to 2.6. Interestingly, all cyclones identified with a ratio higher than 4.5 showed stationary characteristics, suggesting this value as the threshold to classify cyclones of this type. Despite the hourly availability, the characteristic scale for cyclones deepening rate in the MR presented a better description when accumulated in $6 \mathrm{~h}$, with typical values from -3 to $-4 \mathrm{hPa}\left(6 \mathrm{~h}^{-1}\right)$.

The main cyclogenesis areas in the MR were correctly identified, as well as the main branches of tracks spreading from them, as extensively described in the literature. Nevertheless, some commonly underestimated regions as the Aegean Sea presented intensified cyclonic activities. In contrast, others as the Black Sea and the eastern Mediterranean areas showed fewer cyclones than expected from the literature. Furthermore, the better description of the subsynopticscale highlighted other relevant active areas of cyclogenesis, such as the coast of Tunisia and Libya. The strong land-sea temperature contrast favours cyclone developing throughout the year with a notable frequency to frame this region among the main cyclogenetic areas of the MR.

The analysis of the day-by-day values and trends of the main cyclone features during the annual cycle allowed identifying of three different periods with well-defined relationships between the parameters considered. The first is the Cyclogenetic High Season, which starts from the 1st and 2nd week of April and lasts from 10 to 12 weeks. This period is characterised by more than one cyclogenesis per day and more than three active cyclones in the MR, propagating with the highest mean velocities and deepening rates of the year, even without present intense minimums MSLP.

The Thermal Low Season starts in the 2nd and 3rd week of September and lasts 8-9 weeks producing at least two active cyclones and one cyclogenesis per day. Due to the warm nature, the typical cyclone of this season figures between the mildest within the entire annual cycle, moving slowly along short tracks predominantly over the continent, with durations barely longer than $24 \mathrm{~h}$. Finally, the annual cycle ends with the Deep Low Season, which lasts from early October until mid-March. In this period, although less frequent, cyclones present long tracks spreading over the Mediterranean Sea again, where contrasts of temperature to migratory polar air masses create ideal conditions for deepening storms, producing the most intense cyclones of the year, often associated with hydro-meteorological hazards.

In conclusion, it's important to highlight the ERA5 ReAnalysis dataset continues to be updated through the C3S, allowing a continuous expansion of the study period. Another possibility is also exploiting a recently published dataset, the ReAnalysis ERA5 back-extension, which covers a precedent period from 1950 to 1978 . Thus, the study period could be expanded to cover more than 70 years, but it still depends on data validation once they were designed based on significantly less atmospheric information. Furthermore, it is recommended to apply the CDTM using data from other atmospheric models with different spatial and temporal resolutions, adapting the search radius whenever necessary to meet the metrics proposed for the Mediterranean region. The current version of our CDTM may be applied worldwide without modifications for regions where cyclones usually present a well-defined structure (e.g., openocean areas). On the other hand, we recommend its use after careful tuning for regions with complex physiography and other singularities.

Acknowledgements This work is carried out under the framework of OPERANDUM (OPEn-air laboRAtories for Nature baseD solUtions to Manage hydro-meteo risks) project, which is funded by the European Union's Horizon 2020 research and innovation programme under the Grant Agreement No: 776848. The authors thank ECMWF and Copernicus for making the ERA5 dataset available.

Funding Open access funding provided by Alma Mater Studiorum Università di Bologna within the CRUI-CARE Agreement.

Open Access This article is licensed under a Creative Commons Attribution 4.0 International License, which permits use, sharing, adaptation, distribution and reproduction in any medium or format, as long as you give appropriate credit to the original author(s) and the source, provide a link to the Creative Commons licence, and indicate if changes were made. The images or other third party material in this article are included in the article's Creative Commons licence, unless indicated otherwise in a credit line to the material. If material is not included in the article's Creative Commons licence and your intended use is not permitted by statutory regulation or exceeds the permitted use, you will need to obtain permission directly from the copyright holder. To view a copy of this licence, visit http://creativecommons.org/licenses/by/4.0/.

\section{References}

Almazroui M, AM Awad (2016) Synoptic regimes associated with the eastern Mediterranean wet season cyclone tracks. J Atmos Res 180:92-118. https://doi.org/10.1016/j.atmosres.2016.05.015

Befort DJ, Wild S, Kruschke T, Ulbrich U, Leckebusch GC (2016) Different long-term trends of extra-tropical cyclones and windstorms in ERA-20 C and NOAA-20CR reanalyses. Atmos Sci Lett 17:586-595. https://doi.org/10.1002/as1.694

Bladé I, Liebmann B, Fortuny D, van Oldenborgh GJ (2012) Observed and simulated impacts of the summer NAO in Europe: implications for projected drying in the Mediterranean region. Clim Dyn 39:709-727. https://doi.org/10.1007/s00382-011-1195-x

Blender R, Schubert M (2000) Cyclone tracking in different spatial and temporal resolutions. Mon Weather Rev 128:377-384

Blender R, Fraedrich K, Lunkeit F (1997) Identification of cyclonetrack regimes in the North Atlantic. QJR Meteorol Soc 123:727741. https://doi.org/10.1002/qj.49712353910 
Buzzi A, Tibaldi S (1978) Cyclogenesis in the lee of the Alps: a case study. QJR Meteorol Soc 104:271-287. https://doi.org/10.1002/ qj. 49710444004

Campins J, Genovés A, Picornell MA, A Jansà (2011) Climatology of Mediterranean cyclones using the ERA-40 dataset. Int J Climatol 31:1596-1614. https://doi.org/10.1002/joc.2183

Catto JL, Ackerley D, Booth JF, Champion AJ, Colle BA, Pfahl S, Pinto JG, Quinting JF (2019) The future of midlatitude cyclones. Curr Clim Change Rep 5:407-420. https://doi.org/10.1007/ s40641-019-00149-4

Cavicchia L, von Storch H, Gualdi S (2014) A long-term climatology of medicanes. Clim Dyn 43:1183-1195. https://doi.org/10.1007/ s00382-013-1893-7

Dee DP, Uppala SM, Simmons AJ, Berrisford P, Poli P, Kobayashi S, Andrae U, Balmaseda MA, Balsamo G, Bauer P, Bechtold P, Beljaars ACM, van de Berg L, Bidlot J, Bormann N, Delsol C, Dragani R, Fuentes M, Geer AJ, Haimberger L, Healy SB, Hersbach H, Hólm EV, Isaksen L, Kållberg P, Köhler M, Matricardi M, McNally AP, Monge-Sanz BM, Morcrette JJ, Park BK, Peubey C, de Rosnay P, Tavolato C, Thépaut JN, Vitart F (2011) The ERA-Interim reanalysis: configuration and performance of the data assimilation system. QJR Meteorol Soc 137:553-597. https:// doi.org/10.1002/qj.828

Dullaart JCM, Muis S, Bloemendaal N, Aerts JCJH (2020) Advancing global storm surge modelling using the new ERA5 climate reanalysis. Clim Dyn 54:1007-1021. https://doi.org/10.1007/ s00382-019-05044-0

Flaounas E, Kotroni V, Lagouvardos K, Flaounas I (2014) CycloTRACK (v1.0)-tracking winter extratropical cyclones based on relative vorticity: sensitivity to data filtering and other relevant parameters. Geosci Model Dev 7:1841-1853. https://doi. org/10.5194/gmd-7-1841-2014

Flocas HA (1996) Cyclogenesis over the Aegean Sea: identification and synoptic categories. Meteorol Appl 3:53-61. https://doi.org/ $10.1002 /$ met.5060030106

Giorgi F (2006) Climate change hot-spots. Geophys Res Lett 33:L08707. https://doi.org/10.1029/2006GL025734

Hanley J, Caballero R (2012) Objective identification and tracking of multicentre cyclones in the ERAInterim reanalysis data set. QJR Meteorol Soc 138:612-625. https://doi.org/10.1002/qj.948

Hersbach H, Bell B, Berrisford P, Hirahara S, Horányi A, MuñozSabater J, Nicolas J, Peubey C, Radu R, Schepers D, Simmons A, Soci C, Abdalla S, Abellan X, Balsamo G, Bechtold P, Biavati G, Bidlot J, Bonavita M, De Chiara G, Dahlgren P, Dee D, Diamantakis M, Dragani R, Flemming J, Forbes R, Fuentes M, Geer A, Haimberger L, Healy S, Hogan RJ, Hólm E, Janisková M, Keeley S, Laloyaux P, Lopez P, Lupu C, Radnoti G, de Rosnay P, Rozum I, Vamborg F, Villaume S, Thépaut J-N (2020) The ERA5 global reanalysis. QJR Meteorol Soc. https://doi.org/10.1002/qj.3803

Hewson TD, Titley HA (2010) Objective identification, typing and tracking of the complete life-cycles of cyclonic features at high spatial resolution. Meteorol Appl 17:355-381. https://doi.org/10. 1002/met.204

Hodges KI, Hoskins BJ, Boyle J, Thorncroft C (2003) A comparison of recent reanalysis datasets using objective feature tracking: storm tracks and tropical easterly waves. Mon Weather Rev 131:2012-2037. https://doi.org/10.1175/1520-0493(2003)131< 2012:ACORRD>2.0.CO;2

Hoskins BJ (1990) On the existence of storm-tracks. J Atmos Sci 47:1854-1864. https://doi.org/10.1175/1520-0469(1990)047< 1854:OTEOST>2.0.CO;2

Lambert SJ (1988) A cyclone climatology of the Canadian Climate Centre general circulation model. J Clim 1:109-115. https://doi. org/10.1175/1520-0442(1988)001<0109:ACCOTC>2.0.CO;2

Leckebusch GC, Ulbrich U, Fröhlich L, Pinto JG (2007) Property loss potentials for European midlatitude storms in a changing climate. Geophys Res Lett 34:L05703. https://doi.org/10.1029/ 2006GL027663

Lei Y, Letu H, Shang H, Shi J (2020) Cloud cover over the Tibetan Plateau and eastern China: a comparison of ERA5 and ERA-Interim with satellite observations. Clim Dyn 54:2941-2957. https://doi. org/10.1007/s00382-020-05149-x

Liberato MLR, Pinto JG, Trigo IF, Trigo RM (2011) Klaus-an exceptional winter storm over northern Iberia and southern France. Weather 66:330-334. https://doi.org/10.1002/wea.755

Lionello P, Trigo IF, Gil V, Liberato MLR, Nissen KM, Pinto JG, Raible CC, Reale M, Tanzarella A, Trigo RM, Ulbrich S, Ulbrich U (2016) Objective climatology of cyclones in the Mediterranean region: a consensus view among methods with different system identification and tracking criteria. Tellus A: dynamic meteorology oceanography 68:29391. https://doi.org/10.3402/tellusa.v68. 29391

Marra AC, Federico S, Montopoli M, Avolio E, Baldini L, Casella D, D'Adderio LP, Dietrich S, Sanò P, Torcasio RC, Panegrossi G (2019) The precipitation structure of the Mediterranean tropicallike cyclone Numa: analysis of GPM observations and numerical weather prediction model simulations. Remote Sens 11:1690. https://doi.org/10.3390/rs11141690

Messmer M, Gomez-Navarro JJ, Raible CC (2015) Climatology of Vb-cyclones, physical mechanisms and their impact on extreme precipitation over Central Europe. Earth Syst Dyn 6:541-553. https://doi.org/10.5194/esd-6-541-2015

Murray RJ, Simmonds I (1991) A numerical scheme for tracking cyclone centres from digital data. Part I: development and operation of the scheme. Aust Meteorol Mag 39:155-166

Neu U, Akperov MG, Bellenbaum N, Benestad R, Blender R, Caballero R, Cocozza A, Dacre HF, Feng Y, Fraedrich K, Grieger J, Gulev S, Hanley J, Hewson T, Inatsu M, Keay K, Kew SF, Kindem I, Leckebusch GC, Liberato MLR, Lionello P, Mokhov II, Pinto JG, Raible CC, Reale M, Rudeva I, Schuster M, Simmonds I, Sinclair M, Sprenger M, Tilinina ND, Trigo IF, Ulbrich S, Ulbrich U, Wang XL, Wernli H (2013) IMILAST - a community effort to intercompare extratropical cyclone detection and tracking algorithms: assessing method-related uncertainties. Bull Am Meteorol Soc 94:529-547. https://doi.org/10.1175/BAMS-D-11-00154.1

Nielsen JW, Dole RM (1992) A survey of extratropical cyclone characteristics during GALE. Mon Weather Rev 120:1156-1168. https:// doi.org/10.1175/1520-0493(1992)120<1156:ASOECC > 2.0.CO;2

Nissen KM, Leckebusch GC, Pinto JG, Ulbrich U (2014) Mediterranean cyclones and windstorms in a changing climate. Reg Environ Change 14:1873-1890. https://doi.org/10.1007/ s10113-012-0400-8

Pinto JG, Spangehl T, Ulbrich U, Speth P (2005) Sensitivities of a cyclone detection and tracking algorithm: individual tracks and climatology. Meteorol Z 14:823-838. https://doi.org/10.1127/ 0941-2948/2005/0068

Pinto JG, Ulbrich U, Leckebusch GC, Spangehl T, Reyers M, Zacharias S (2007) Changes in storm track and cyclone activity in three SRES ensemble experiments with the ECHAM5/MPIOM1 GCM. Clim Dyn 29:195-210. https://doi.org/10.1007/ s00382-007-0230-4

Porcù F, Carrassi A (2009) Toward an estimation of the relationship between cyclonic structures and damages at the ground in Europe. Nat Hazards Earth Syst Sci 9:823-829. https://doi.org/10.5194/ nhess-9-823-2009

Priestley MDK, Ackerley D, Catto JL, Hodges KI, McDonald RE, Lee RW (2020) An overview of the extratropical storm tracks in CMIP6 historical simulations. J Clim 33:6315-6343. https://doi. org/10.1175/JCLI-D-19-0928.1

Raible CC, Ziv B, Saaroni H, Wild M (2010) Winter synoptic-scale variability over the Mediterranean Basin under future climate 
conditions as simulated by the ECHAM5. Clim Dyn 35:473-488. https://doi.org/10.1007/s00382-009-0678-5

Raible CC, Della-Marta PM, Schwierz C, Wernli H (2008) Northern Hemisphere extratropical cyclones: a comparison of detection and tracking methods and different reanalyses. Mon Weather Rev 136:880-897. https://doi.org/10.1175/2007MWR2143.1

Rohrer M, Martius O, Raible CC, Brönnimann S (2020) Sensitivity of blocks and cyclones in ERA5 to spatial resolution and definition. Geophys Res Lett. https://doi.org/10.1029/2019GL085582

Sanders F (1980) Synoptic-dynamic climatology of the "Bomb." Mon Weather Rev 108:1589-1606. https://doi.org/10.1175/15200493(1980) $108<1589:$ SDCOT $>2.0 . C O ; 2$

Simmonds I, Burke C, Keay K (2008) Arctic climate change as manifest in cyclone behavior. J Clim 21:5777-5796. https://doi.org/10. 1175/2008JCLI2366.1

Sinclair MR (1994) An objective cyclone climatology for the Southern Hemisphere. Mon Weather Rev 122:2239-2256. https://doi.org/ 10.1175/1520-0493(1994)122<2239:AOCCFT>2.0.CO;2

Taszarek M, Kendzierski S, Pilguj N (2020) Hazardous weather affecting European airports: climatological estimates of situations with limited visibility, thunderstorm, low-level wind shear and snowfall from ERA5. Weather Clim Extremes 28:100243. https://doi.org/ 10.1016/j.wace.2020.100243
Trigo IF (2006) Climatology and interannual variability of storm-tracks in the Euro-Atlantic sector: a comparison between ERA-40 and NCEP/NCAR reanalyses. Clim Dyn 26:127-143. https://doi.org/ 10.1007/s00382-005-0065-9

Trigo IF, Bigg GR, Davies TD (2002) Climatology of cyclogenesis mechanisms in the Mediterranean. Mon Weather Rev 130:549 569. https://doi.org/10.1175/1520-0493(2002)130<0549:COCMI $\mathrm{T}>2.0 . \mathrm{CO} ; 2$

Trigo IF, Davies TD, Bigg GR (1999) Objective climatology of cyclones in the Mediterranean region. J Clim 12:1685-1696. https://doi.org/10.1175/1520-0442(1999)012<1685:OCOCIT $>2$. $0 . \mathrm{CO} ; 2$

Wernli H (2006) Surface cyclones in the ERA-40 dataset (1958-2001). Part I: novel identification method and global climatology. J Atmos Sci 63:2486-2507. https://doi.org/10.1175/JAS3766.1

Publisher's Note Springer Nature remains neutral with regard to jurisdictional claims in published maps and institutional affiliations. 